FINAL REPORT

U. S. Department of Energy

\title{
Measurements and Models for Hazardous Chemical and Mixed Wastes
}

Principal Investigators: Laurel A. Watts and Cynthia D. Holcomb

National Institute of Standards and Technology, Boulder, Colorado 80305

Collaborators: Stephanie L. Outcalt and Beverly Louie, National Institute of

Standards and Technology, Boulder, Colorado 80305

Michael E. Mullins and Tony N. Rogers, Michigan Technological University, Houghton, Michigan

Grant Number: A107-97ER14838

Project Number: 60155

Technical Program Officer: George J. Schneider

Project Duration: October, 1997 to June, 2002 


\section{Table of Contents}

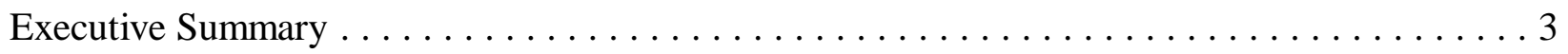

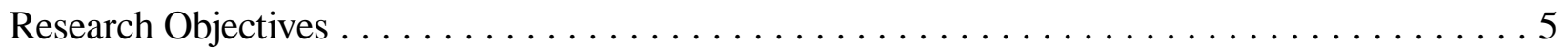

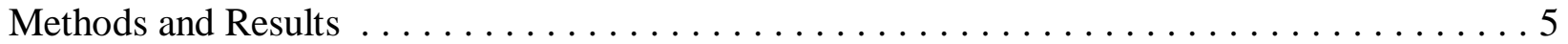

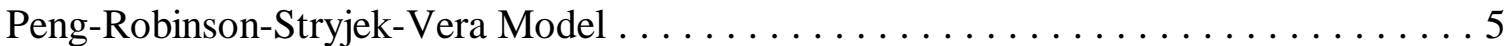

NIST Measurements for Water + Acetone +2 -Propanol $+\mathrm{NaNO}_{3} \ldots \ldots \ldots \ldots \ldots$

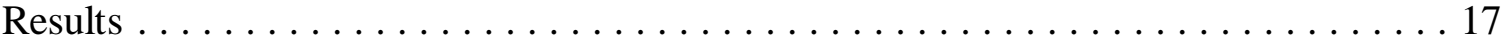

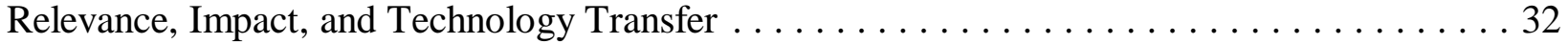

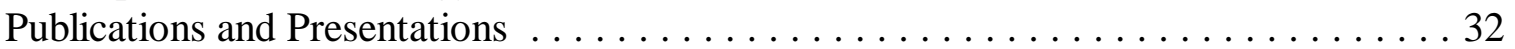

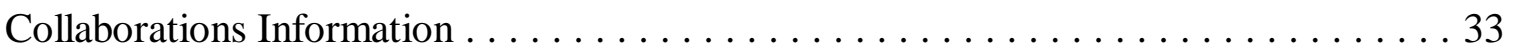

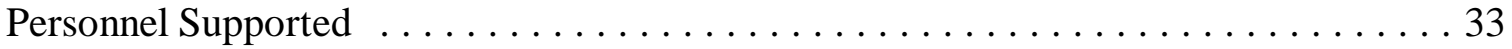

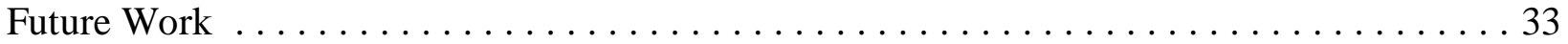

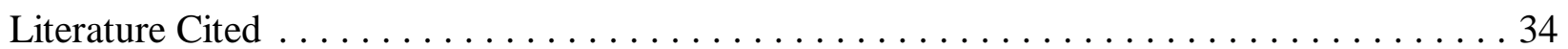




\section{Executive Summary}

Mixed solvent aqueous waste of various chemical compositions constitutes a significant fraction of the total waste produced by industry in the United States. Not only does the chemical process industry create large quantities of aqueous waste, but the majority of the waste inventory at the Department of Energy (DoE) sites previously used for nuclear weapons production is mixed solvent aqueous waste. In addition, large quantities of waste are expected to be generated in the clean-up of those sites. In order to effectively treat, safely handle, and properly dispose of these wastes, accurate and comprehensive knowledge of basic thermophysical properties is essential.

The goal of this work is to develop a phase equilibrium model for mixed solvent aqueous solutions containing salts. An equation of state was sought for these mixtures that a) would require a minimum of adjustable parameters and b) could be obtained from available data or data that were easily measured. A model was developed to predict vapor composition and pressure given the liquid composition and temperature. It is based on the Peng-Robinson equation of state, adapted to include non-volatile and salt components. The model itself is capable of predicting the vapor-liquid equilibria of a wide variety of systems composed of water, organic solvents, salts, nonvolitile solutes, and acids or bases. The representative system of water + acetone + 2-propanol $+\mathrm{NaNO}_{3}$ was selected to test and verify the model. Vapor-liquid equilibrium and phase density measurements were performed for this system and its constituent binaries.

\section{Model}

The Peng-Robinson-Stryjek-Vera (PRSV, 1986a, 1986b) equation of state with the Wong-Sandler (1992) mixing rules is used to predict the vapor-liquid equilibrium of mixed solvent electrolyte solutions. The Wong-Sandler mixing rules require the excess Gibbs free energy and the liquid phase activity coefficients. These activity coefficients are the sum of a short-range local composition contribution and a long-range contribution from ions that are present. The activity coefficient model of Chen et. al. (1986) is used for the local composition part of the excess Gibbs free energy and activity coefficients, and the model of Pitzer and Simonson (1986) is used for the long-range contributions to the excess Gibbs free energy and activity coefficients. The dielectric constant of the aqueous solvent mixture is calculated for the long-range contribution. In addition, the liquid volume is corrected using an empirical formula. The vapor pressure of the solution and the vapor composition are predicted when given the liquid composition and temperature of the solution.

There are two pure-fluid adjustable parameters, one for the equation of state, and the other is a liquid density correction factor. The model contains one solvent-solvent equation of state adjustable parameter, one solvent-solvent dielectric constant parameter, two local composition parameters for each binary, and two adjustable parameters for each solvent-salt 
binary. The model uses no higher-order adjustable parameters to cover a broad range of temperature, pressure and composition. The model is applied to the system water + acetone $+2-$ propanol + sodium nitrate using data obtained as outlined below, and values from the literature. The system has also been extended to include the solvents ethanol and methanol using literature measurements. Details concerning the model can be found in Watts (in preparation).

\section{Measurements}

A dynamic phase equilibrium apparatus (Watts and Louie, 2000) was used to measure the vapor pressure, vapor composition and density, and liquid density of the system water + acetone +2 -propanol $+\mathrm{NaNO}_{3}$, and the constituent binaries. This apparatus is constructed of corrosion resistant materials for all of the wetted parts. Measurements can be performed from 300 to $425 \mathrm{~K}$ (to $700 \mathrm{~K}$ without density measurements) and to $35 \mathrm{MPa}$. The apparatus consists of an equilibrium cell with a sapphire viewing window, vapor and liquid pumps for recirculation, and two vibrating-tube densimeters. The equilibrium cell and densimeters are housed in an aluminum block to minimize the temperature gradients. The temperature is measured with a standard reference grade $25 \Omega$ PRT in the equilibrium cell wall, and a $100 \Omega$ PRT for each of the densimeters. The temperature was maintained using a convection oven. Measurements for the vapor pressure of water $+\mathrm{NaNO}_{3}$ were performed on a similar apparatus without density measurement capabilities. Measurements were performed from $300 \mathrm{~K}$ to $370 \mathrm{~K}$ for salt concentrations up to 5.6 molal. A detailed analysis of these results are presented in Watts and Outcalt (in preparation).

\section{Results}

In summary, the equation of state developed in this project works very well for predicting the vapor pressure and phase composition of mixtures of water and other solvents, and the description of salts is very promising.

Future work for this research may include developing a better density correlation for the liquid phase, and investigating other local composition models for the Gibbs free energy calculation. Extension of the model to include salt solubility prediction and ionic speciation present in the liquid phase would also be possible. The model could be extended to other fluids and salts of interest. This would involve measuring the VLE and infinite dilution activity coefficient of additional water + organic solvent + salts over a wider range of salt composition. 


\section{Research Objectives}

Mixed solvent aqueous waste of various chemical compositions constitutes a significant fraction of the total waste produced by industry in the United States. Not only does the chemical process industry create large quantities of aqueous waste, but the majority of the waste inventory at the Department of Energy (DoE) sites previously used for nuclear weapons production is mixed solvent aqueous waste. In addition, large quantities of waste are expected to be generated in the clean-up of those sites. In order to effectively treat, safely handle, and properly dispose of these wastes, accurate and comprehensive knowledge of basic thermophysical properties is essential.

The goal of this work is to develop a phase equilibrium model for mixed solvent aqueous solutions containing salts. An equation of state was sought for these mixtures that a) would require a minimum of adjustable parameters and $b$ ) could be obtained from available data or data that were easily measured. A model was developed to predict vapor composition and pressure given the liquid composition and temperature. It is based on the Peng-Robinson equation of state, adapted to include non-volatile and salt components. The model itself is capable of predicting the vapor-liquid equilibria of a wide variety of systems composed of water, organic solvents, salts, nonvolitile solutes, and acids or bases. The representative system of water + acetone +2 propanol $+\mathrm{NaNO}_{3}$ was selected to test and verify the model. Vapor-liquid equilibrium and phasedensity measurements were performed for this system and its constituent binaries.

The specific goals of this project were to:

- develop and validate models that accurately predict the phase equilibria and thermodynamic properties of hazardous aqueous systems necessary for the safe handling and successful design of separation and treatment processes for hazardous chemical and mixed wastes;

- $\quad$ accurately measure the phase equilibria and thermodynamic properties of a representative system (water + acetone+ 2-propanol + sodium nitrate) over the applicable ranges of temperature, pressure, and composition to provide the experimental data required for model development and testing.

\section{Methods and Results}

\section{Peng-Robinson-Stryjek-Vera Model}

The Stryjek and Vera (1986a, 1986b) modification to the Peng-Robinson (1976) cubic equation of state was used as the basis for this work. The Peng-Robinson-Stryjek-Vera (PRSV) cubic equation of state relates the pressure $(P)$ to the molar volume $(v)$ and temperature $(T)$ : 


$$
P=\frac{R T}{v-b_{m}}-\frac{a_{m}}{v^{2}+2 v b_{m}-b_{m}^{2}}
$$

with the pure fluid energy parameter $a$

$$
a_{i}=\left(0.457235 R^{2} T_{c i}^{2} / P_{c i}\right) \alpha_{i}
$$

and the pure fluid excluded volume parameter $b_{i}$

$$
b=0.077796 R T_{c i} / P_{c i}
$$

where $\alpha_{\mathrm{i}}$ is

$$
\alpha_{i}=\left[1+\kappa_{i}\left(1-T_{R i}^{0.5}\right)\right]
$$

In the PRSV equation, the $\kappa_{\mathrm{i}}$ term is determined by

$$
\kappa_{i}=\kappa_{o i}+\kappa_{1 i}\left(1+T_{R i}^{0.5}\right)\left(0.7-T_{R i}\right)
$$

where

$$
\kappa_{o i}=0.378893+1.4897153 \omega_{i}-0.17131848 \omega_{i}^{2}+0.0196554 \omega_{i}^{3}
$$

and $\kappa_{1 \mathrm{i}}$ is a empirical pure fluid parameter, $\omega_{i}$ is the Pitzer acentric factor, and $T_{R i}$ is the reduced temperature, defined as $T_{R i}=T / T_{c i}$.

The excluded volume parameter $\left(b_{i}\right)$ for ionic species is obtained from the CarnahanStarling type equation of Zuo and Guo (1991):

$$
b_{i}=(2 / 3) \pi N_{A} \sigma_{i}^{3}
$$

where $N_{A}$ is Avogadro's number, and $\sigma_{\mathrm{i}}$ is the ionic diameter of the cation or anion. The energy parameter for ionic species is obtained from the development of Zhao and Lu (1998):

$$
a_{i}=Z_{M i} V_{0 i} R T\left[\exp \left(\varepsilon_{i} / 2 k T\right)-1\right]
$$


where $k$ is Boltzmann's constant, $Z_{\mathrm{Mi}}$ is the lattice coordination number (18 for the ionic species of interest here), and $V_{0 \mathrm{i}}$ is the ionic excluded volume, defined as:

$$
V_{0 i}=N_{A} \sigma_{i}^{3} / \sqrt{2}
$$

$\mathcal{E} / k$ is the Lennard-Jones energy parameter (Harvey and Prausnitz, 1989):

$$
\varepsilon_{i} / k=2.2789 \times 10^{-11} Z_{i}^{1 / 2} \alpha p_{i}^{3 / 2} \sigma_{i}^{-6} .
$$

The units on $\varepsilon / k$ are $\mathrm{K} \cdot \mathrm{m}^{3 / 2}, Z_{\mathrm{i}}$ is the absolute value of the ionic charge, and $\alpha p_{\mathrm{i}}$ is the ionic polarizability.

In this model, an accurate liquid density is needed for the proper determination of the phase equilibria. The simple empirical correction of Mathias et.al. (1989) is applied. The corrected molar volume is given by

$$
v^{c o r r}=v^{P R S V}+s+f\left(\frac{0.41}{0.41+\delta}\right)
$$

where $\delta$ is the bulk modulus of the fluid and is defined as

$$
\delta=-\frac{v^{2}}{R T}\left(\frac{\partial P}{\partial v}\right)_{T} \text {. }
$$

The function $f_{\mathrm{c}}$ is selected to obtain the true critical volume

$$
\begin{aligned}
f_{c} & =v_{c}-\left(v_{c}^{P R S V}+s\right) \\
v_{c}^{P R S V} & =3.946 b
\end{aligned}
$$

The adjustable parameter $s$ is fit to pure fluid density data, and may be temperature dependent with the form

$$
s=c_{0}+c_{1} / T
$$

where $c_{0}$ and $c_{1}$ are empirical constants.

\section{Mixing Rules}


Mixing rules are used in cubic equations of state to provide a method of obtaining the $a, b$ and $s$ parameters for the overall mixture. The mixing rules of Wong and Sandler (1992) are used for both the neutral and ionic species. The Wong-Sandler mixing rules for the PRSV equation of state are given by

$$
b_{m}=\frac{\sum_{i} \sum_{j} x_{i} x_{j}\left(b-\frac{a}{R T}\right)_{i j}}{\left(1-\sum_{i} x_{i} \frac{a_{i}}{b_{i} R T}+\frac{A_{\infty}^{E}}{C R T}\right)}
$$

and

$$
\frac{a_{m}}{R T}=\frac{\sum_{i} \sum_{j} x_{i} x_{j}\left(b-\frac{a}{R T}\right)_{i j}\left(\sum_{k} x_{k} \frac{a_{k}}{b_{k} R T}+\frac{A_{\infty}^{E}}{C R T}\right)}{\left(1-\sum_{i} x_{i} \frac{a_{i}}{b_{i} R T}+\frac{A_{\infty}^{E}}{C R T}\right)}
$$

with

$$
\left(b-\frac{a}{R T}\right)_{i j}=\frac{\left(b_{i}-\frac{a_{i}}{R T}\right)+\left(b_{j}-\frac{a_{j}}{R T}\right)}{2}\left(1-k_{i j}\right)
$$

where $k_{i j}$ is a mixing parameter.

The Wong-Sandler mixing rules use the relationship:

$$
G^{E}=A^{E}+P V^{E}
$$

relating the excess Helmholtz free energy to the excess Gibbs free energy, and the approximation that for low pressure the $V^{\mathrm{E}}$ term is small. This allows the direct application of excess Gibbs free energy formulations to the mixing rules. When ions are present in solution, the excess Gibbs free energy is often divided into long- and short-range contributions. The long-range contributions are usually modeled using a Debye-Huckel formulation as modified by Pitzer (PDH, Pitzer and Simonson, 1986). The short-range contributions are modeled using local composition equations. The excess Gibbs free energy then takes on the form of a sum:

$$
\frac{g^{E}}{R T}=\frac{g^{E, P D H}}{R T}+\frac{g^{E, L C}}{R T} \text {. }
$$


The mixing rule for the volume correction terms $s$ and $v_{\mathrm{c}}$ are given by the simple rules:

$$
s_{m}=\sum_{i} x_{i} s_{i} \text { and } v_{c m}=\sum_{i} x_{i} v_{c i}
$$

\section{Long-Range Force Model}

The long-range force contribution to the excess Gibbs free energy is the Debye-Huckel term of Pitzer and Simonson (1986), and is

$$
\frac{g^{P D H}}{R T}=-\left(\sum_{i} x_{i}\right)\left(1 / M_{s}\right)^{1 / 2}\left(4 A_{\varphi} I_{x} / \rho\right) \ln \left(1+\rho I_{x}^{1 / 2}\right)
$$

where $M_{\mathrm{s}}$ is the solvent average molecular weight, and $\rho$ is related to the solvent hard-core diameter, and is taken as a constant equal to $14.9 \mathrm{~nm} . I_{\mathrm{x}}$ is the mole fraction based ionic strength, and is defined as:

$$
I_{x}=\frac{1}{2} \sum_{i} x_{i} z_{i}^{2}
$$

where $z_{\mathrm{i}}$ is the ionic charge. The Debye-Huckel parameter $\mathrm{A}_{\varphi}$ is

$$
A_{\varphi}=(1 / 3)\left(2 \pi N_{A} d_{s}\right)^{1 / 2}\left(e^{2} / 4 \pi \varepsilon_{0} D_{s} k T\right)^{3 / 2}
$$

where $d_{\mathrm{s}}$ and $D_{\mathrm{s}}$ are the solvent density and dielectric constant, respectively. The term $4 \pi \varepsilon_{0}$ is the permitivity of free space, and $e$ is the charge on an electron.

The long-range part of the activity coefficients for the solvent components and the ions are:

$$
\begin{aligned}
& \ln \gamma_{s}^{D H}=2 A_{\varphi}\left(1 / M_{s}\right)^{1 / 2} I_{x}^{3 / 2} /\left(1+\rho I_{x}^{1 / 2}\right) \\
& \ln \gamma_{i}^{D H}=-z_{i}^{2} A_{\varphi}\left(1 / M_{s}\right)^{1 / 2}\left[(2 / \rho) \ln \left(1+\rho I_{x}^{1 / 2}\right)+I_{x}^{1 / 2}\left(1-2 I_{x} / z_{i}^{2}\right) /\left(1+\rho I_{x}^{1 / 2}\right)\right]
\end{aligned}
$$

The solvent density is obtained from the equation of state, and is used here to calculate the solvent mixture dielectric constant using the method of Harvey and Prausnitz (1987). This adds one binary interaction coefficient, $\delta_{i j}$. Local Composition Model

The short-range forces for the excess Gibbs free energy are modeled with the non-random two-liquid model (NRTL) of Renon and Prausnitz (1968). This model was extended to electrolyte 
solutions by Chen and Evans (1986) and developed for phase equilibria for mixed solvent electrolytes by Mock et al. (1986).

The excess Gibbs free energy is given by:

$$
\begin{aligned}
\frac{g^{E, L C}}{R T} & =\sum_{m} X_{m} \frac{\sum_{j} X_{j} G_{j m} \tau_{j m}}{\sum_{k} X_{k} G_{k m}}+\sum_{c} X_{c} \sum_{a^{\prime}} \frac{X_{a^{\prime}} \sum_{j} X_{j} G_{j c, a^{\prime} c} \tau_{j c, a^{\prime} c}}{\sum_{a^{\prime \prime}} X_{a^{\prime \prime}} \sum_{k} X_{k} G_{k c a^{\prime} c}} \\
& +\sum_{a} X_{a} \sum_{c^{\prime}} \frac{X_{c^{\prime}} \sum_{j} X_{j} G_{j a, c^{\prime} a} \tau_{j a, c^{\prime} a}}{\sum_{c^{\prime \prime}} X_{c^{\prime \prime}} \sum_{k} X_{k} G_{k a, c^{\prime} a}}
\end{aligned}
$$

In the above equation, the subscript $m$ is molecular (uncharged) species, $j$ and $k$ are any species, and $c$ and $a$ are cations and anions respectively. The local composition mole fraction $\left(X_{\mathrm{j}}\right)$ is charge-adjusted for ionic species, and is defined as:

$$
X_{j}=x_{j} C_{j}
$$

where $C_{j}$ is the absolute value of the charge for the ionic species, and unity for uncharged species. The NRTL parameters $G_{i j}$ and $\tau_{i j}$ are temperature-dependent binary parameters related through the equation:

$$
G_{i j}=\exp \left(\alpha_{i j} \tau_{i j}\right)
$$

The non-randomness factor, $\alpha_{i j}$ is set equal to 0.3 for this work. Two methods of modeling the temperature dependence of $\tau_{i j}$ were tested. The first is the method outlined in Chen and Evans (1986):

$$
\tau_{i, j}=a_{1}+a_{2}\left(\frac{1}{T}-\frac{1}{\theta}\right)+a_{3}\left[\left(\frac{\theta-T}{T}\right)+\ln \left(\frac{T}{\theta}\right)\right]
$$

where $a_{1}, a_{2}$ and $a_{3}$ are empirical constants, and $\theta$ is the reference temperature, $298.15 \mathrm{~K}$, for this work. An alternative is to fit the NRTL energy parameter $\left(g_{i j}-g_{i j}\right)$ directly and obtain $\tau_{i j}$ from the relationship:

$$
\tau_{i j}=\frac{g_{i j}-g_{j j}}{R T}
$$

The activity coefficients are obtained by taking the appropriate derivative of the excess Gibbs free energy. 


\section{Model Parameters}

The pure-fluid parameters for the equation of state are the critical constants $\left(T_{c}, P_{c}\right.$ and $\left.v_{c}\right)$, the molecular weight, the acentric factor $\left(\omega_{i}\right)$, an empirical pure-fluid parameter $\left(\kappa_{\mathrm{i}}\right)$, the dipole moment, the polarizability, and the pure fluid density correction parameters $\left(c_{0}\right.$ and $\left.c_{l}\right) . \kappa_{\mathrm{i}}$ is fit to each fluid using vapor pressure data over the range of temperature of interest. The density parameters are obtained by fitting to liquid density data over the pressure range of interest. The ionic species require the molecular weight, charge, ionic diameter $\left(\sigma_{i}\right)$ and polarizability $\left(\alpha_{i}\right)$. All of these parameters are obtained from basic properties of the ions and are not fit to the model.

The binary interaction parameters include the $k_{i j}$ introduced in the Wong-Sandler mixing rules, $\delta_{i j}$ from the dielectric constant calculation, and the NRTL parameters for $\tau_{i j}$. The $\delta_{i j}$ values obtained by Harvey and Prausnitz (1987) are used. The other parameters are obtained by optimizing the liquid phase activity or osmotic coefficients obtained from vapor pressure and vapor composition measurements from the literature, or measured at NIST and presented in the following section. Orthogonal distance regression methods are used to obtain these parameters for this model using verified data. The parameters for the system water + acetone +2 -propanol + $\mathrm{NaNO}_{3}$ are included below, along with the parameters for methanol and ethanol. The pure fluid $\kappa_{\mathrm{i}}$ parameter and the density parameters are presented in Table I. The binary interaction parameters for the PRSV solvent-solvent interactions are presented in Table II, and the NRTL energy parameters are presented in Table III. The binary interaction parameters for the dielectric constant are presented in Table IV.

Table I. Optimized pure solvent PRSV and density parameters.

\begin{tabular}{||l||r|r|r||}
\hline \multicolumn{1}{|c||}{ Solvent } & $\kappa_{\mathrm{i}}$ & $c_{0}$ (density) & \multicolumn{1}{c|}{$c_{1}$ (density) } \\
\hline \hline water & -0.06635 & $-4.884 \times 10^{-6}$ & $5.518 \times 10^{-4}$ \\
\hline acetone & -0.00888 & $-6.874 \times 10^{-6}$ & $-2.405 \times 10^{-3}$ \\
\hline 2-propanol & 0.23264 & $-1.538 \times 10^{-6}$ & $-1.653 \times 10^{-4}$ \\
\hline methanol & -0.16816 & $-6.5 \times 10^{-6}$ & 0.0 \\
\hline ethanol & -0.03374 & $-3.117 \times 10^{-6}$ & 0.0 \\
\hline
\end{tabular}


Table II. Optimized PRSV binary interaction parameters $k_{i j}$ for solvent-solvent interactions.

\begin{tabular}{||l|l|l|l|l|l||}
\hline \multicolumn{1}{|c|}{ Solvent } & \multicolumn{1}{c|}{ water } & \multicolumn{1}{c|}{ acetone } & \multicolumn{1}{c|}{ 2-propanol } & \multicolumn{1}{c|}{ methanol } & \multicolumn{1}{c|}{ ethanol } \\
\hline \hline water & 0 & 0.2454 & 0.3333 & 0.1088 & 0.2548 \\
\hline acetone & 0.2454 & 0 & 0.0625 & 0.1139 & 0.0310 \\
\hline 2-propanol & 0.3333 & 0.0625 & 0 & 0.0239 & -0.0033 \\
\hline methanol & 0.1088 & 0.1139 & 0.0239 & 0 & 0.0245 \\
\hline ethanol & 0.2548 & 0.0310 & -0.0033 & 0.0245 & 0 \\
\hline
\end{tabular}

Table III. Optimized NRTL binary interaction parameters $\left(g_{i j}-g_{i j}\right) / 1000$.

\begin{tabular}{||l|c|c|c|c|c|c||}
\hline \hline $\mathrm{i}$ & water & acetone & 2-propanol & methanol & ethanol & NaNO3 \\
\hline \hline acetone & 2.095 & 0 & 1.756 & 1.427 & -0.264 & -0.325 \\
\hline 2-propanol & 0.0464 & -0.0866 & 0 & 2.066 & 0.200 & 0.173 \\
\hline methanol & -0.8049 & 0.2977 & -1.970 & 0 & -1.010 & na \\
\hline ethanol & -0.2050 & 2.051 & -0.300 & 1.093 & 0 & 8.76 \\
\hline $\mathrm{NaNO}_{3}$ & 2.060 & 2.38 & -0.016 & na & 15.5 & 0 \\
\hline \hline
\end{tabular}

Table IV. Optimized dielectric binary interaction parameter $\delta_{i j}$ for solvent-solvent interactions.

\begin{tabular}{||l|c|c|c|c|c||}
\hline \multicolumn{1}{|c|}{ Solvent } & water & acetone & 2-propanol & methanol & ethanol \\
\hline \hline water & 0.000 & 0.042 & -0.151 & 0.046 & -0.038 \\
\hline acetone & 0.042 & 0.000 & 0.000 & -0.041 & 0.000 \\
\hline 2-propanol & -0.151 & 0.000 & 0.000 & 0.000 & 0.000 \\
\hline methanol & 0.046 & -0.041 & 0.000 & 0.000 & -0.014 \\
\hline ethanol & -0.038 & 0.000 & 0.000 & -0.014 & 0.000 \\
\hline
\end{tabular}

Additional details concerning the model and determination of the parameters can be found in Watts (in preparation). 


\section{NIST Measurements for Water + Acetone + 2-Propanol + $\mathrm{NaNO}_{3}$}

A dynamic phase equilibrium apparatus (Watts and Louie, 2000) was used to measure the vapor pressure, vapor composition and density, and liquid density of the system water + acetone +2 -propanol $+\mathrm{NaNO}_{3}$, and the constituent binaries. This apparatus is constructed of corrosion-resistant materials for all of the wetted parts. Measurements can be performed from 300 to $425 \mathrm{~K}$ (to $700 \mathrm{~K}$ without density measurements) and to $35 \mathrm{MPa}$. The apparatus consists of an equilibrium cell with a sapphire viewing window, vapor and liquid pumps for recirculation, and two vibrating-tube densimeters. The equilibrium cell and densimeters are housed in an aluminum block to minimize the temperature gradients. The temperature is measured with a standard reference grade $25 \Omega$ PRT in the equilibrium cell wall, and a $100 \Omega$ PRT for each of the densimeters. The temperature was maintained using a convection oven. Measurements for the vapor pressure of water $+\mathrm{NaNO}_{3}$ were performed on a similar apparatus without density measurement capabilities. Measurements were performed from $300 \mathrm{~K}$ to $370 \mathrm{~K}$ for salt concentrations up to 5.6 molal. The full description of the VLE apparatus is presented in Watts and Louie (2000). The measurement results are presented in Table V.

The first set of measurements are the vapor pressures (bubble points) of mixtures of water $+\mathrm{NaNO}_{3}$. These measurements were made in a small-volume VLE apparatus. The main components of the apparatus are an equilibrium cell and a vapor recirculation pump. This apparatus has an equilibrium cell of approximately $30 \mathrm{~cm}^{3}$ volume, which is roughly one-tenth of the volume of the cells in the high-accuracy vapor-liquid equilibrium apparatus used for the remaining experiments. The components are immersed in a bath of heat-transfer fluid contained within a strip-silvered Dewar vessel. The bath temperature is measured with a standard platinum resistance thermometer, and pressure measurements are made with a commercially available pressure transducer. The temperature range of the apparatus is $260-400 \mathrm{~K}$, with pressures to approximately $6 \mathrm{MPa}$. The accuracy of the temperature measurement is $\pm 0.03 \mathrm{~K}$, and the pressure measurements are accurate to $\pm 0.1 \%$ of the pressure. An automated data acquisition system is used to record temperature and pressure at equilibrium.

The remaining data were collected on the azeotropic VLE apparatus. The second set of data are for the water + acetone system at three compositions over the temperature range of 308 $\mathrm{K}$ to $368 \mathrm{~K}$. The next set of data complements this set by adding $\mathrm{NaNO}_{3}$ to the solutions. The fourth and fifth sets of data are for the water +2 -propanol and water +2 -propanol $+\mathrm{NaNO}_{3}$ systems, at only one composition. The final sets of data are for the full system water + acetone + 2-propanol, and water + acetone +2 -propanol $+\mathrm{NaNO}_{3}$. These data, along with published data, are used to evaluate the model, and the results are presented in the following section. A more detailed analysis of these results are presented in Watts and Outcalt (in preparation). 


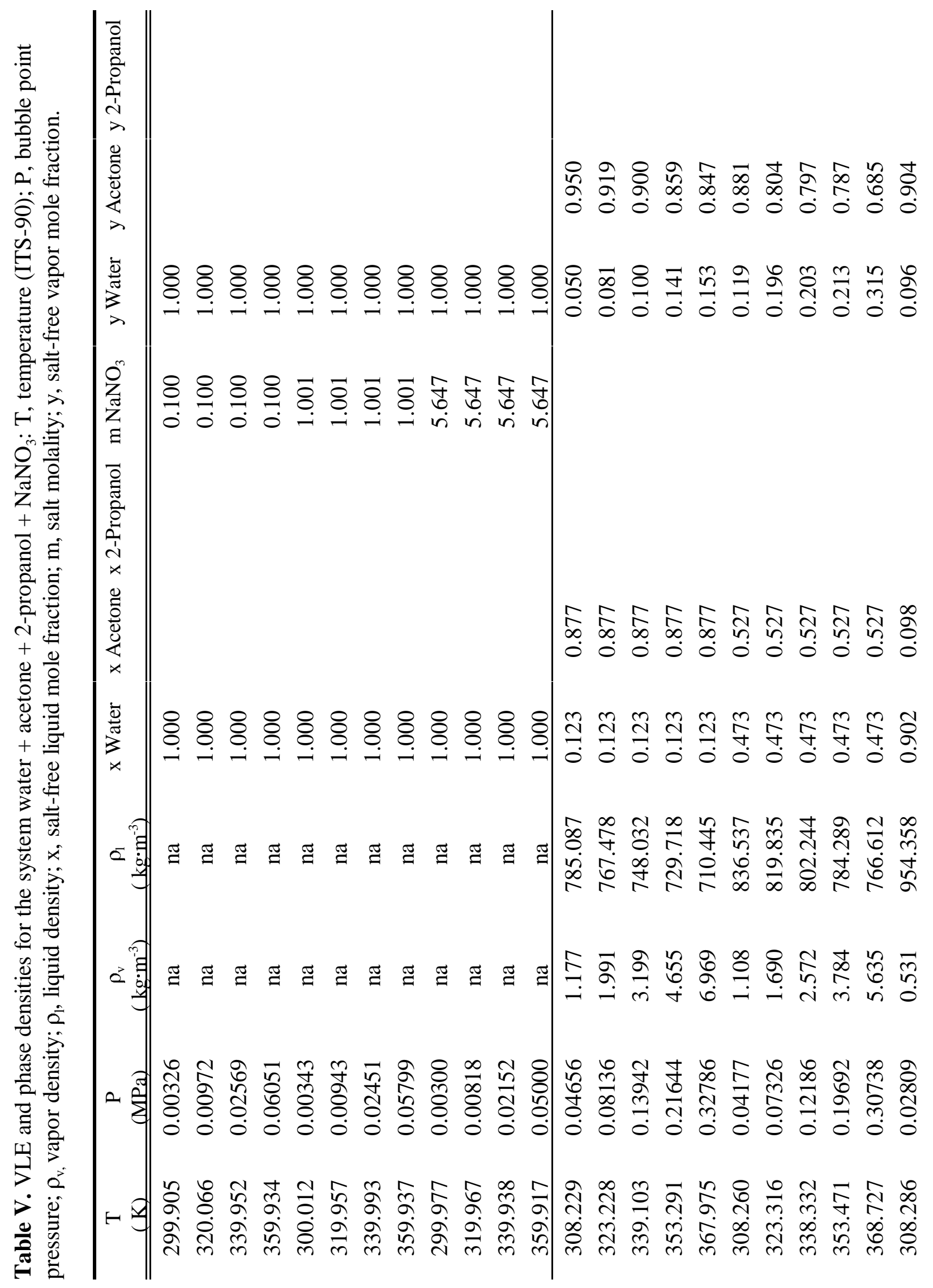




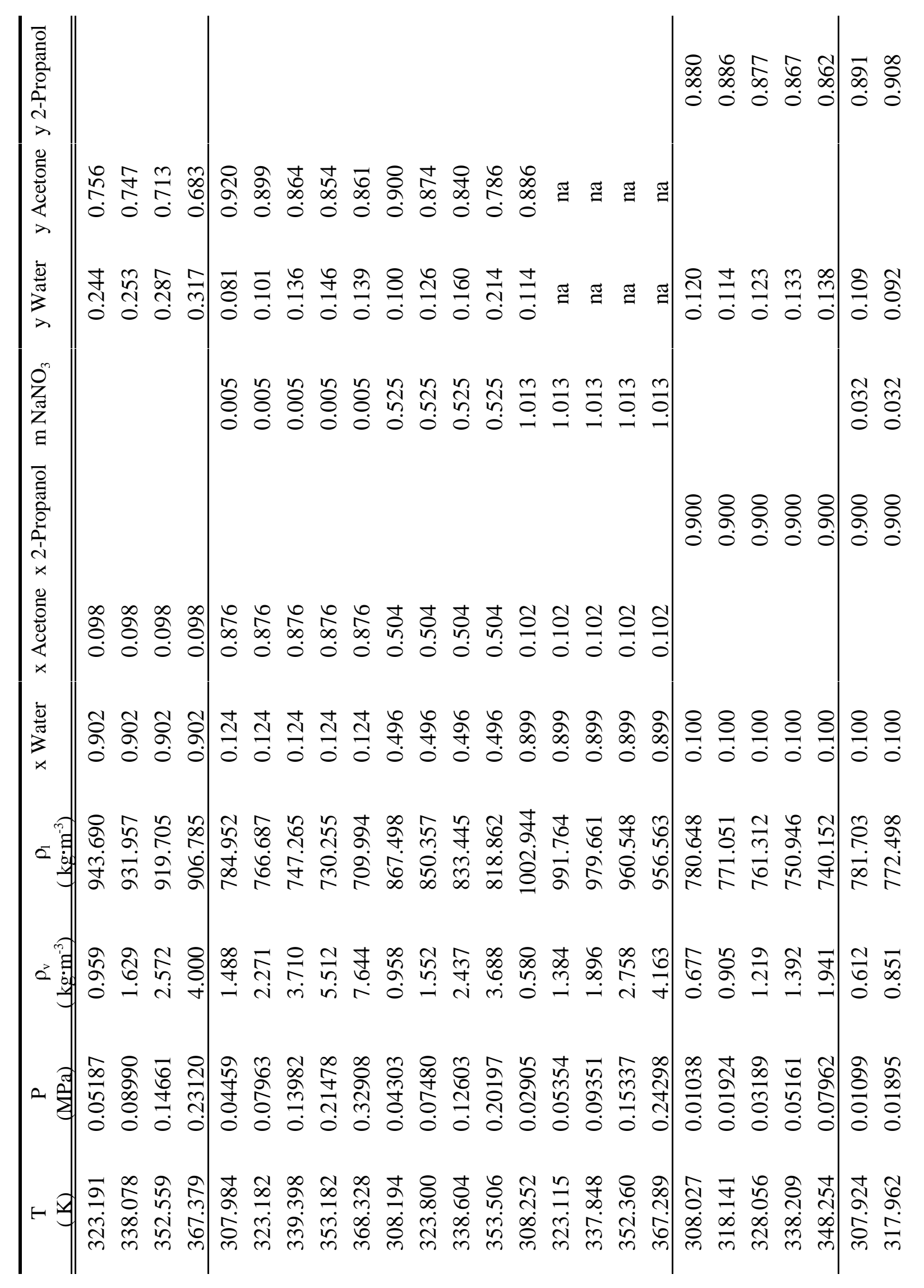




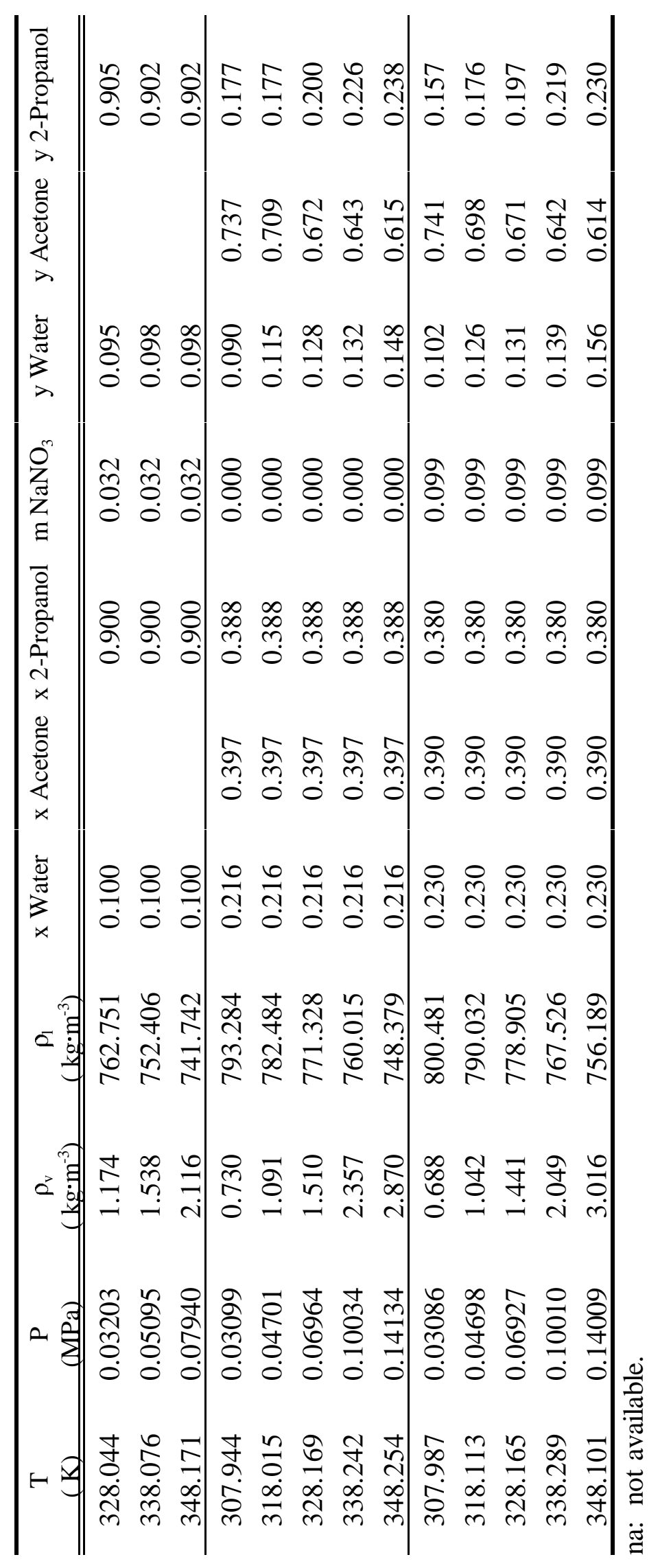




\section{Results}

The results of the modeling are presented in Table VI and Figures 1 through 25 on the pages that follow, and are discussed here for the ability of the model to predict the vapor pressure, phase composition and phase density of the pure solvents, solvent mixtures, and solvent mixtures with salt added. Figures 1 through 11 present the results of modeling the pure fluids (water, acetone, 2-propanol, methanol and ethanol) for the density and the saturated vapor pressure calculations compared to literature data. One of the drawbacks of cubic equations of state is the poor performance in predicting the liquid phase density. In this model, an empirical correction was used to overcome this, as the density is needed to calculate the dielectric constant of the mixture. In most cases the saturated liquid density is reproduced to within $\pm 2 \%$ except in the critical region, which is adequate for the dielectric constant calculation. The equation of state also is acceptable for predicting the compressed liquid density, with a maximum error of $-5 \%$ at $150 \mathrm{MPa}$ for 2-propanol (Figure 11). The model for the vapor pressures of the pure solvents is adequate for present purposes, with a maximum absolute deviation over the range of data less than $2 \%$, and less than $1 \%$ in our region of interest, from 300 to $400 \mathrm{~K}$. Methanol and ethanol exhibited systematic deviations, but it is not clear if the error is in the literature data or the model.

The liquid density calculation of water + acetone is given in Figure 12, and presents both the corrected and uncorrected values predicted by the model. It can be seen that the density correction acts only to offset the density calculated by the equation of state. The density correction factor was developed for a different version of the Peng-Robinson equation of state with traditional mixing rules that do not allow salts to be included in the model. Our model has a maximum in density introduced by the new mixing rules. This causes errors in liquid density of over $20 \%$ even after the correction is applied, and renders this method of obtaining the mixture density of little use. An empirical correlation based on critical properties of the pure fluid is used in the model to obtain the density for the dielectric constant. This is a problem that needs to be solved with future work on the model.

Figures 13 through 18 present the results of modeling the binary solvent mixtures for the saturated vapor pressure and the vapor composition given the liquid composition and temperature. The percent absolute error in the pressure and the average absolute error in the vapor composition are given in Table VI. The bubble point vapor pressure for the mixtures is predicted to within 1.5 to $3.5 \%$ for all of the binary mixtures. The error in the vapor composition ranged from 0.015 to 0.022 mole fraction.

Figure 19 presents the modeling results of the vapor pressure of water $+\mathrm{NaNO}_{3}$ solutions to 27 molal in salt to $400 \mathrm{~K}$. The maximum absolute pressure deviation given in Table VI is $2.8 \%$, and indicates that modeling of a salt solution with an equation of state is usable. The error is largest at high temperature and high salt concentration.

Figures 20 through 23 present the results for modeling binary solvent mixtures with and without $\mathrm{NaNO}_{3}$ present, and the full system of water + acetone + 2-propanol with and without salt are presented in Figures 24 and 25. The error in the bubble point vapor pressure is usually within the range for the binary mixtures, but does show more error at high temperature and high salt concentration. The model predicts that the salt has a stronger effect on the vapor composition than the measured result. The vapor composition is twice the range measured for 
the binary combinations. In this case, the model underpredicts the effect of the salt on the vapor composition compared to the measured result. With low salt composition, the full system was well predicted. When the measurements were made, it was assumed that the high solvent side would be more difficult to predict, but more data that are high in salt and contain small concentrations of solvent would be a more significant test of the model.

Table VI. Correlation of VLE data for mixtures with the model and parameters of this work.

\begin{tabular}{|c|c|c|c|}
\hline System & $\begin{array}{c}\text { Number of data } \\
\text { points }\end{array}$ & $\begin{array}{c}\text { Absolute pressure } \\
\text { deviation, } \% \\
\end{array}$ & $\begin{array}{c}\text { Average absolute } \\
\text { error of } y\end{array}$ \\
\hline Water + acetone & 145 & 3.5 & 0.017 \\
\hline Water + 2-propanol & 229 & 3.0 & 0.015 \\
\hline $\begin{array}{l}\text { Acetone }+2- \\
\text { Propanol }\end{array}$ & 18 & 1.5 & 0.022 \\
\hline Water $+\mathrm{NaNO}_{3}$ & 108 & 2.8 & na \\
\hline $\begin{array}{l}\text { Water }+ \text { acetone }+ \\
\mathrm{NaNO}_{3}\end{array}$ & 15 & 7.4 & 0.039 \\
\hline $\begin{array}{l}\text { Water + 2-propanol + } \\
\mathrm{NaNO}_{3}\end{array}$ & 5 & 2.5 & 0.031 \\
\hline $\begin{array}{l}\text { Water }+ \text { acetone }+2- \\
\text { propanol }+\mathrm{NaNO}_{3}\end{array}$ & 5 & 0.5 & 0.031 \\
\hline \multicolumn{4}{|c|}{ Includes selected literature data as well as results of measurements performed at NIST. } \\
\hline
\end{tabular}




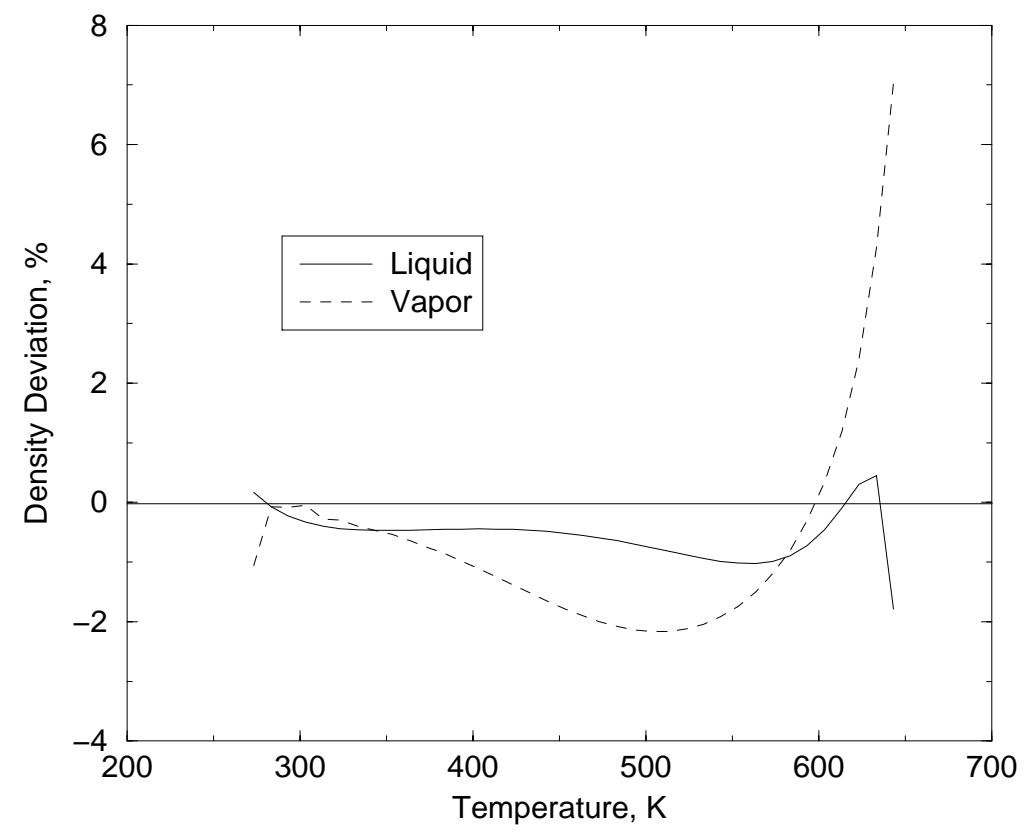

Figure 1. Density deviation of water for the saturated vapor and liquid phases compared to the Saul and Wagner (1989) equation of state.

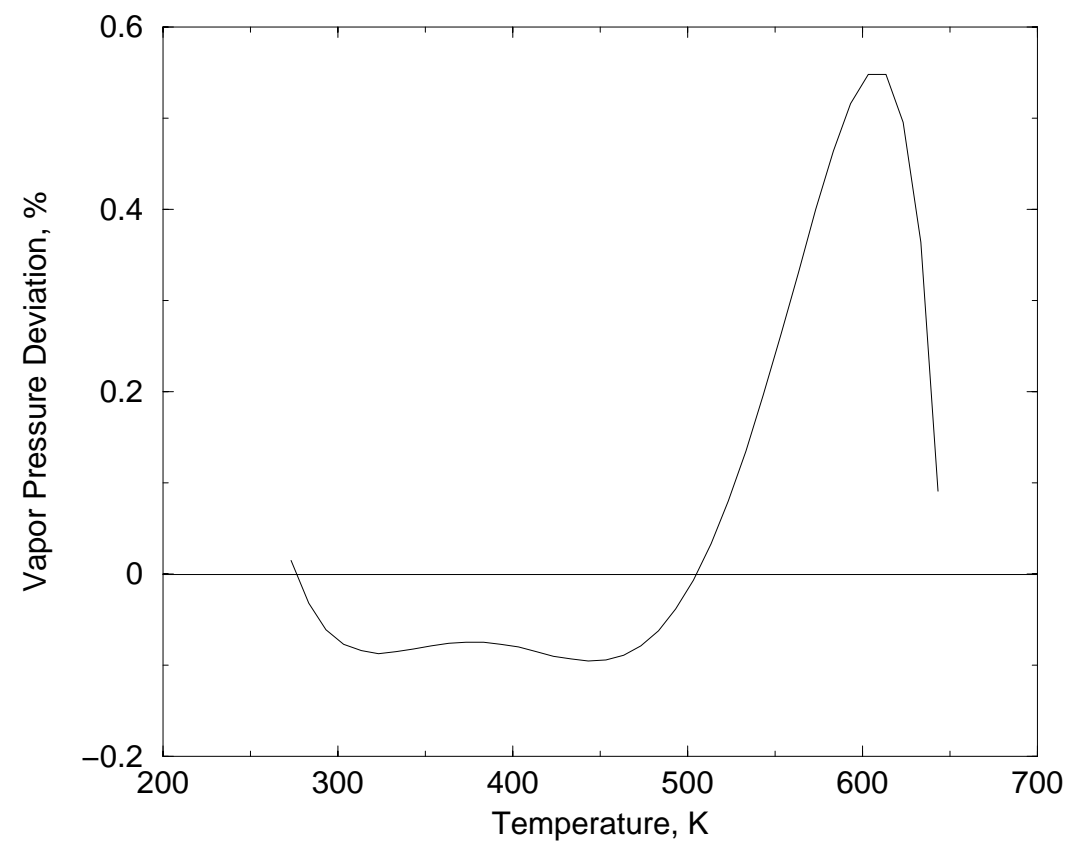

Figure 2. Saturated vapor pressure deviation of water compared to the Saul and Wagner (1989) equation of state. 


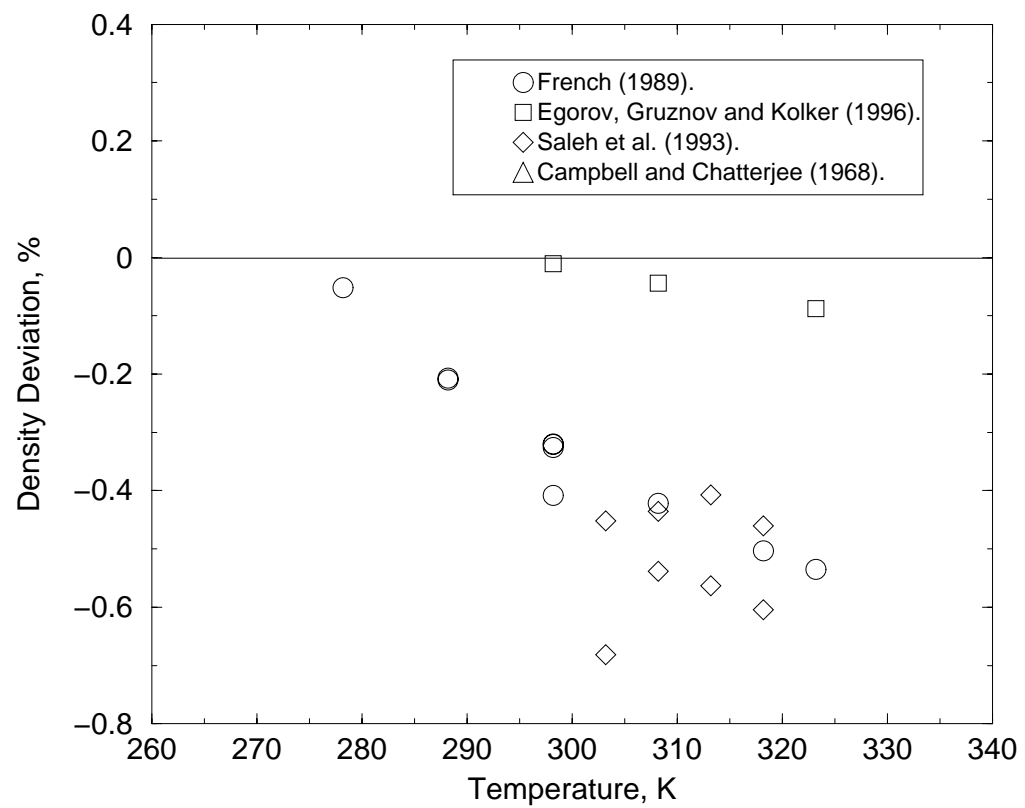

Figure 3. Saturated liquid density deviation of acetone.

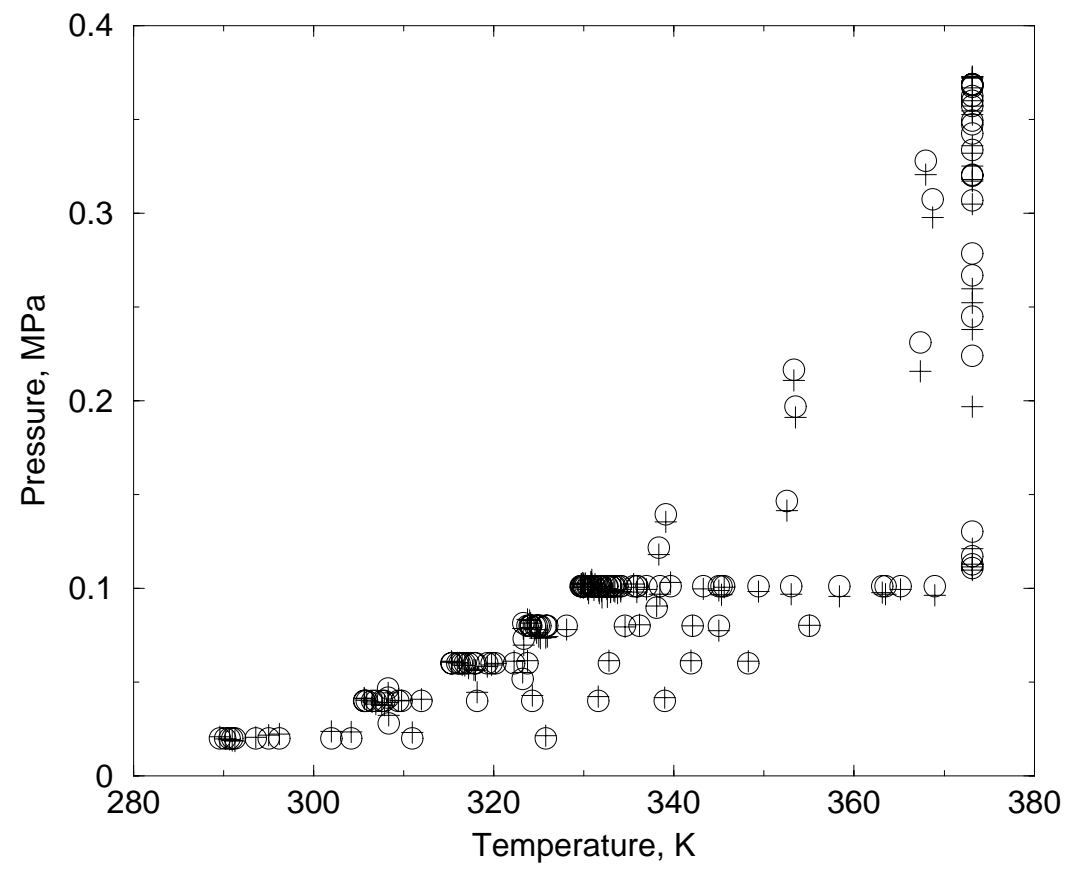

Figure 4. Measured (open symbol) and predicted (+) saturated vapor pressure deviation of acetone. 


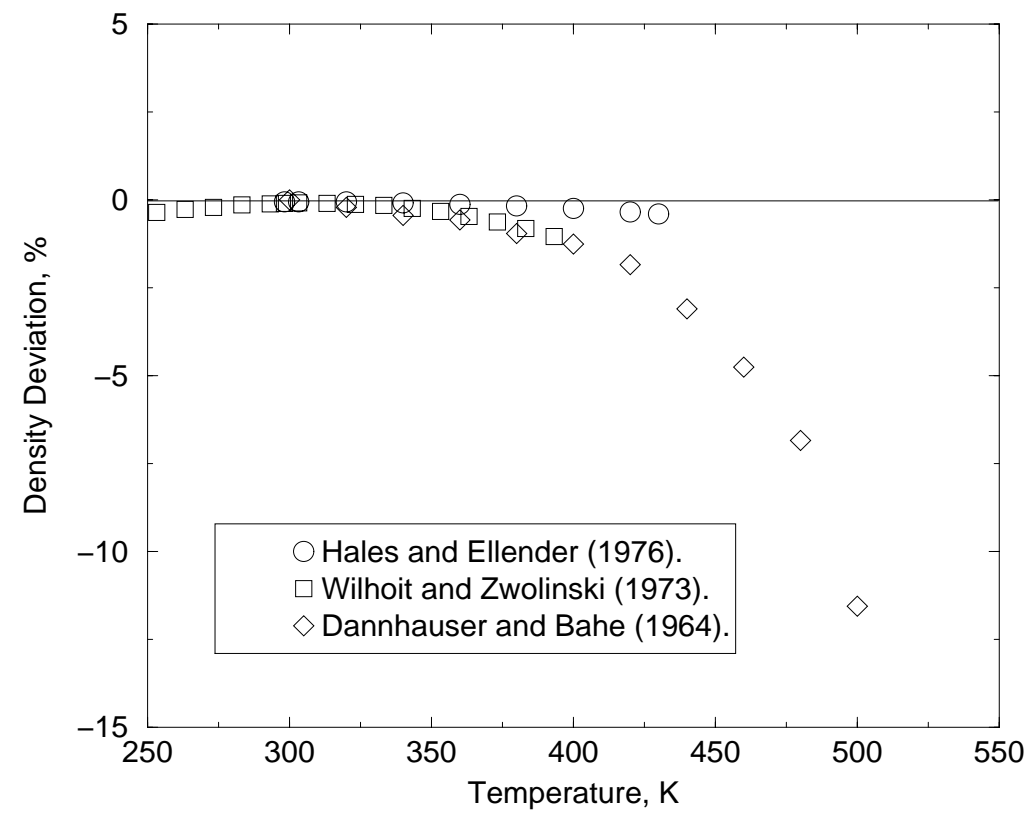

Figure 5. Saturated liquid phase density deviation of 2-propanol.

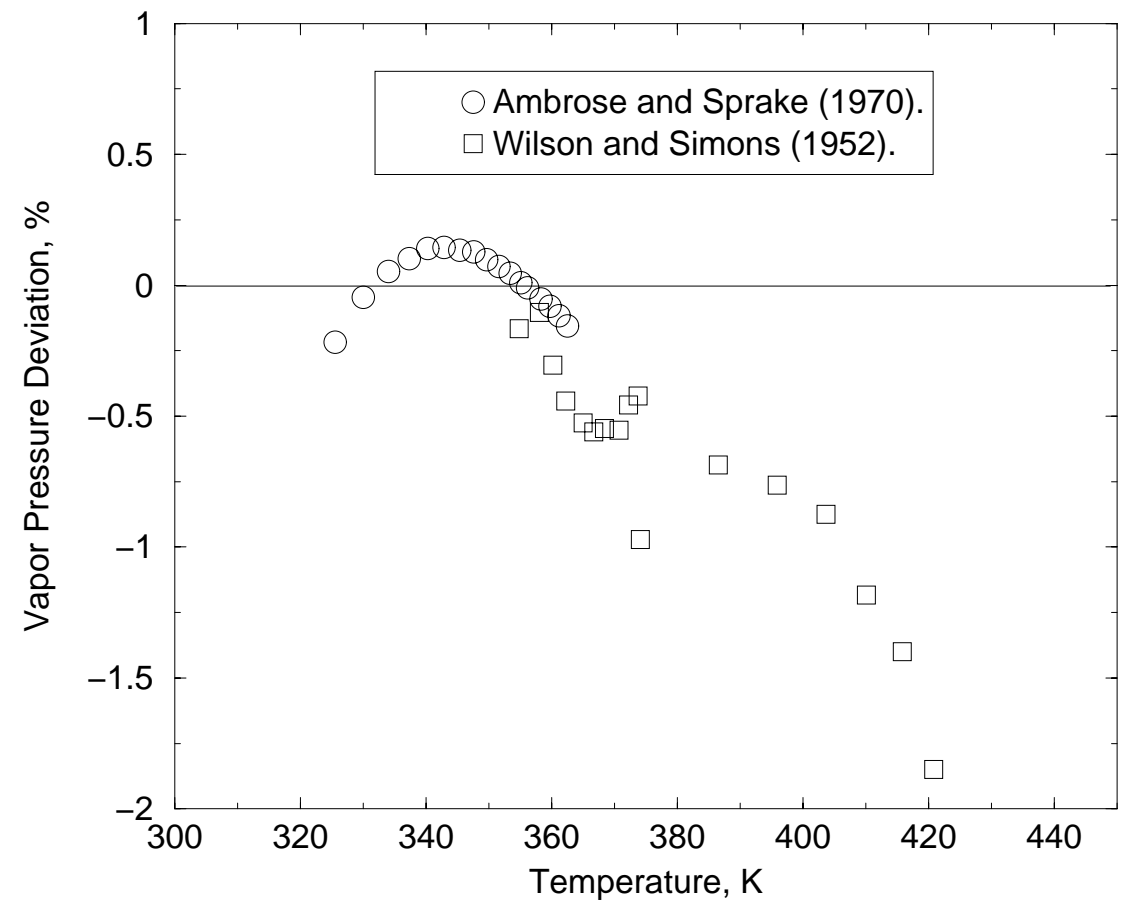

Figure 6. Saturated vapor pressure deviation of 2-propanol. 


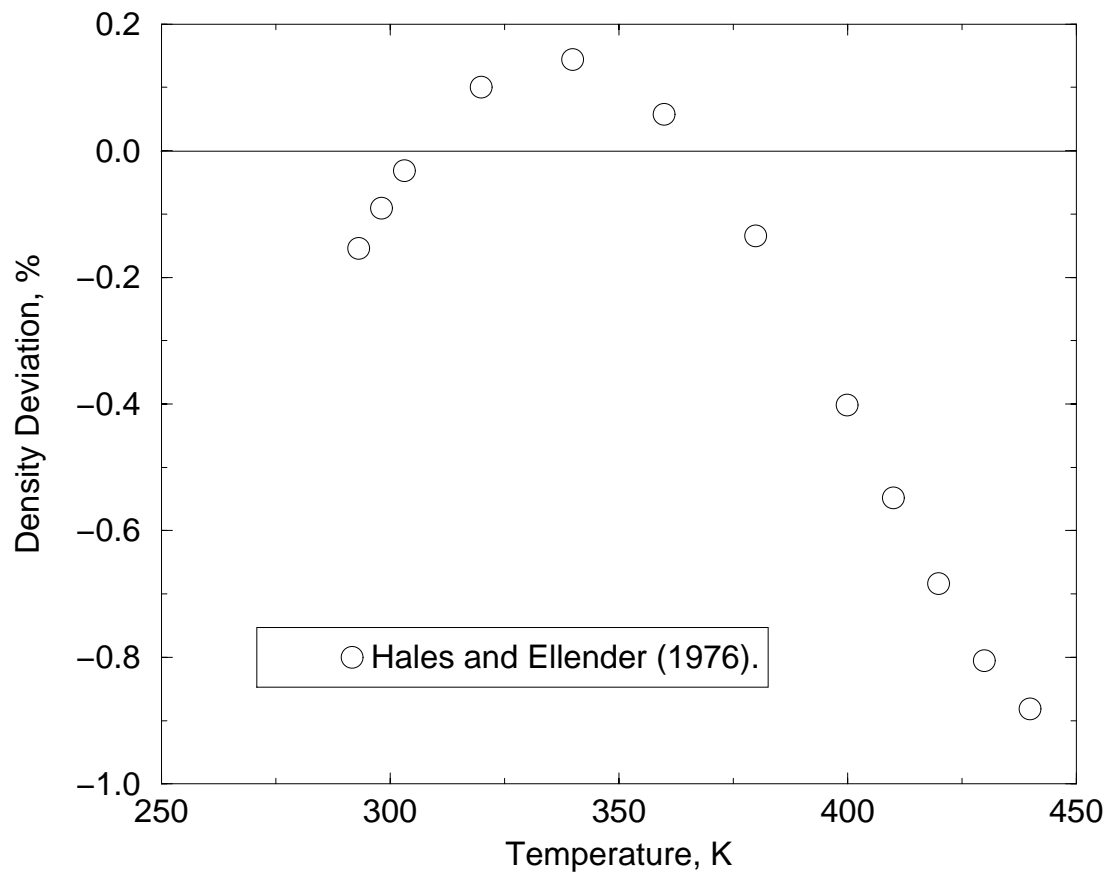

Figure 7. Saturated liquid density deviation of methanol.

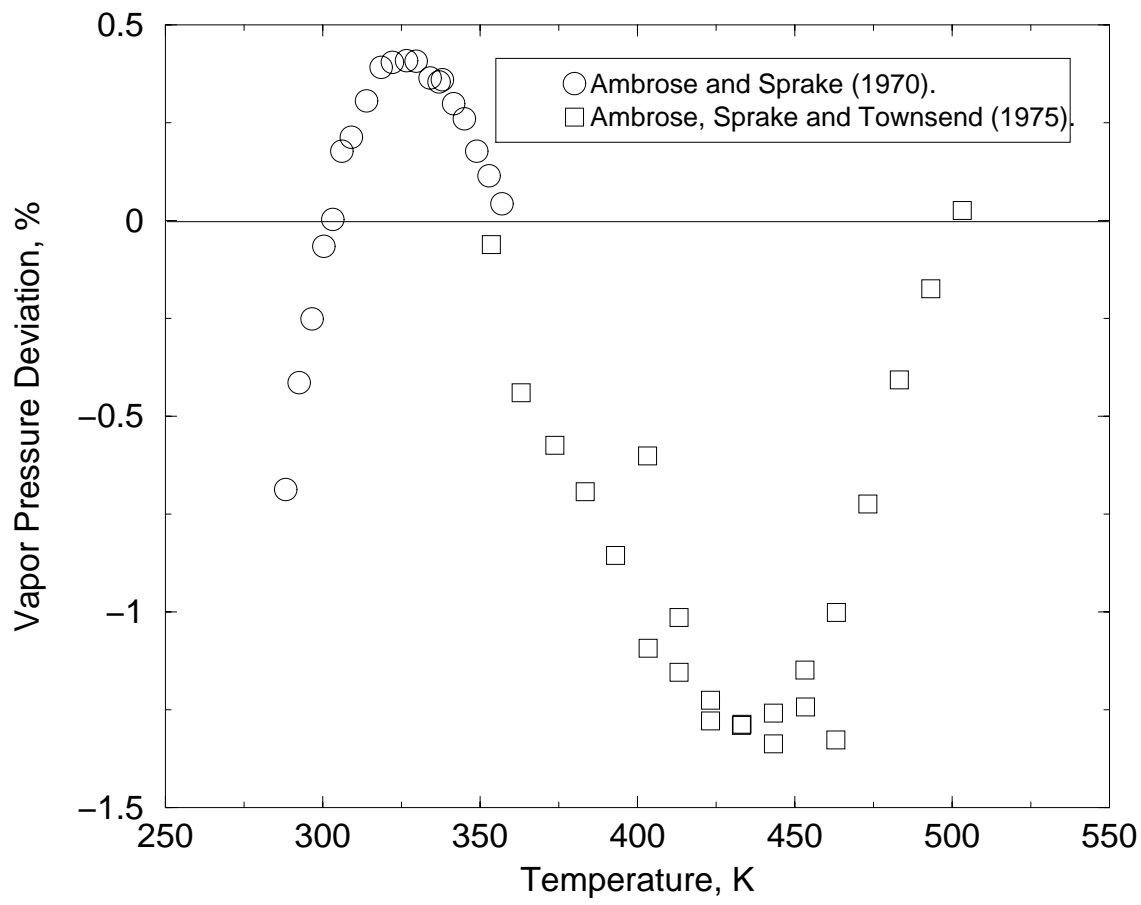

Figure 8. Saturated vapor pressure deviation of methanol. 


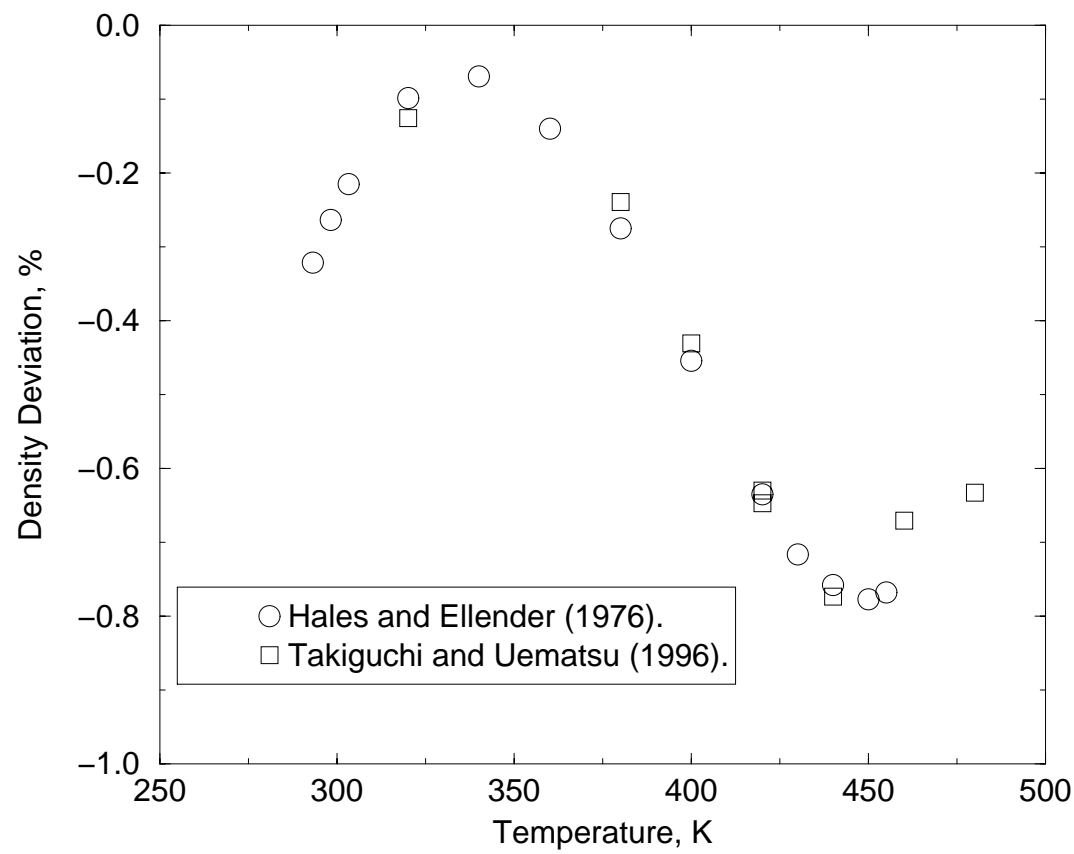

Figure 9. Saturated liquid density deviation of ethanol.

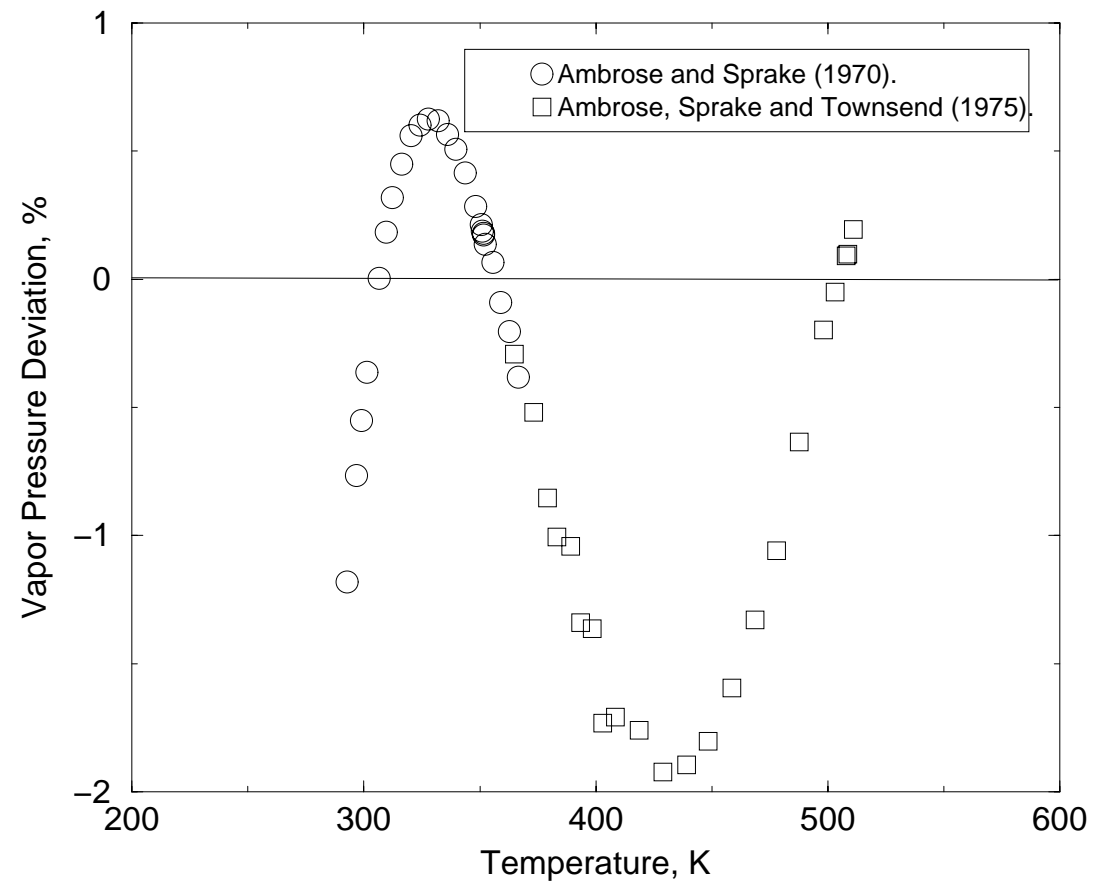

Figure 10. Saturated vapor pressure of ethanol. 


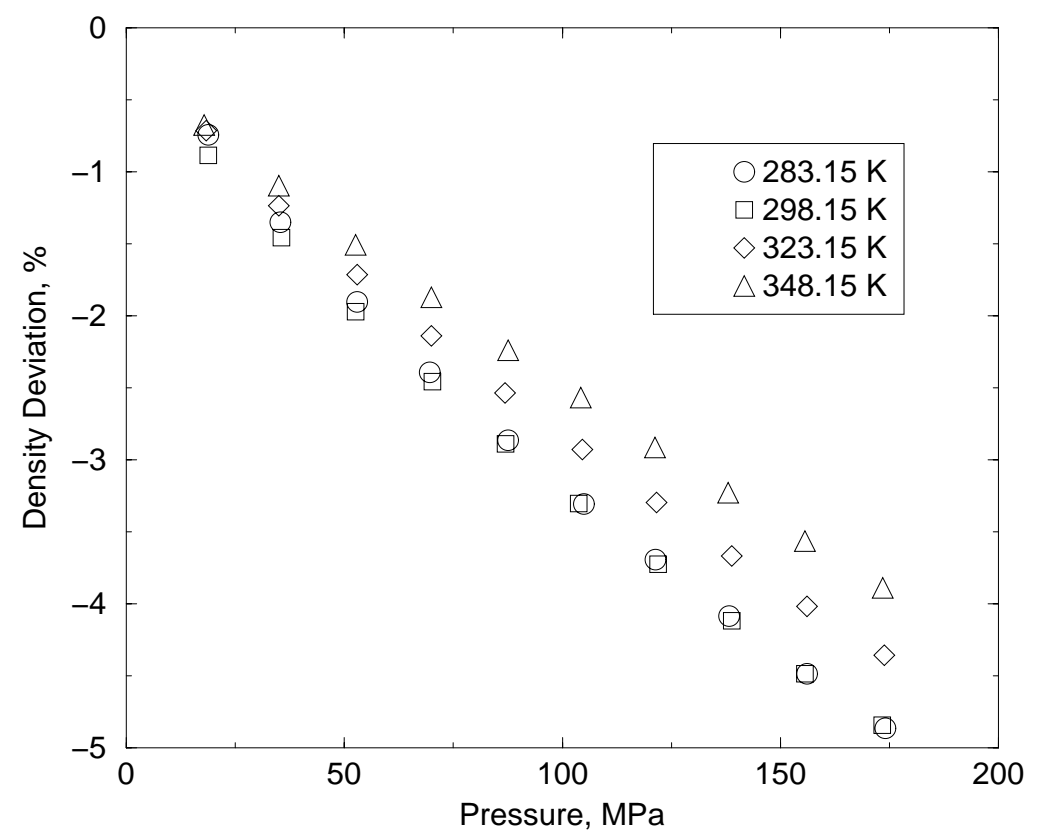

Figure 11. High pressure liquid density of 2-propanol over a range of temperature. Data from Kubotu, Tanaku and Makita (1987).

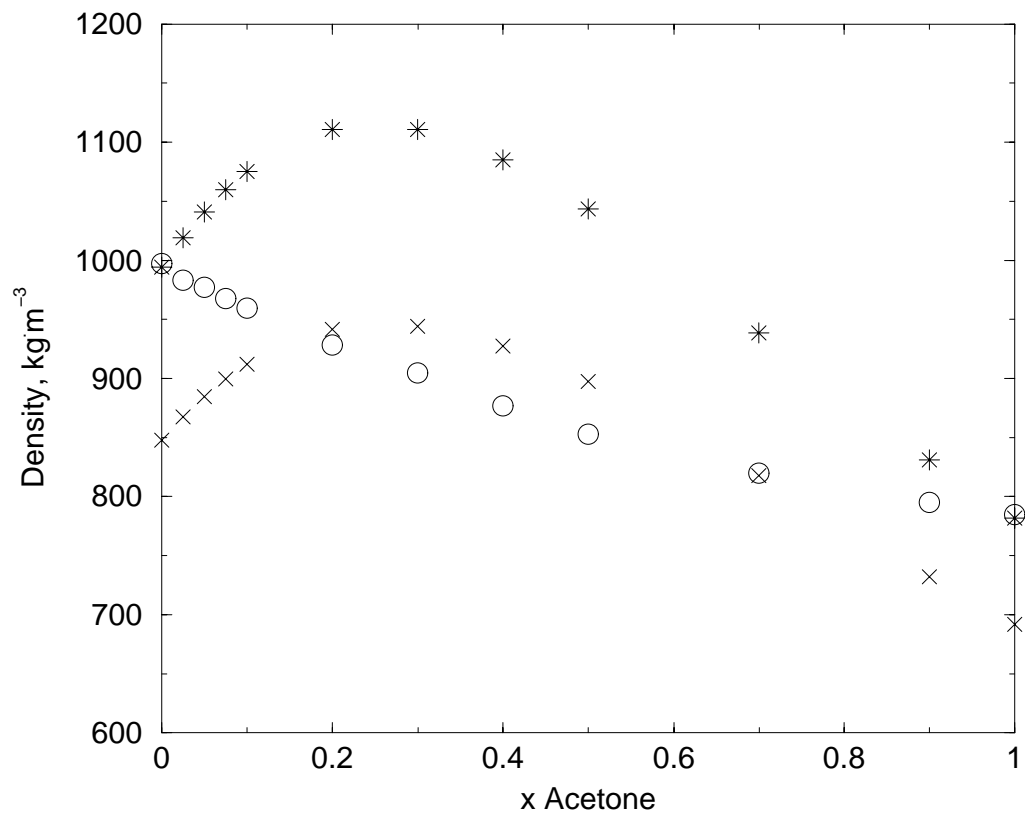

Figure 12. Measured saturated liquid density (open symbol) and predicted results $(X$ uncorrected, * corrected) of mixtures of water + acetone. Data from Kubotu, Tanaku and Makita (1987). 


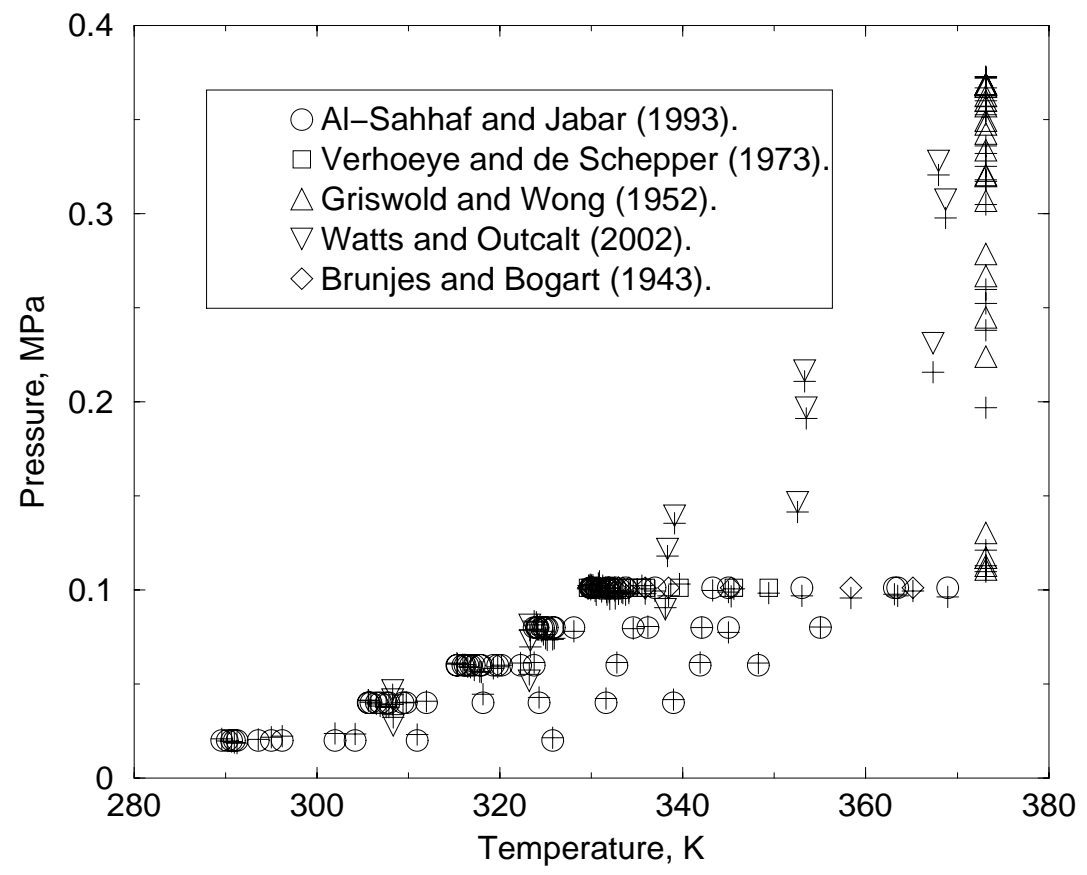

Figure 13. Measured (open symbols) and predicted (+) saturated vapor pressures of water + acetone mixtures over a range of composition and temperature.

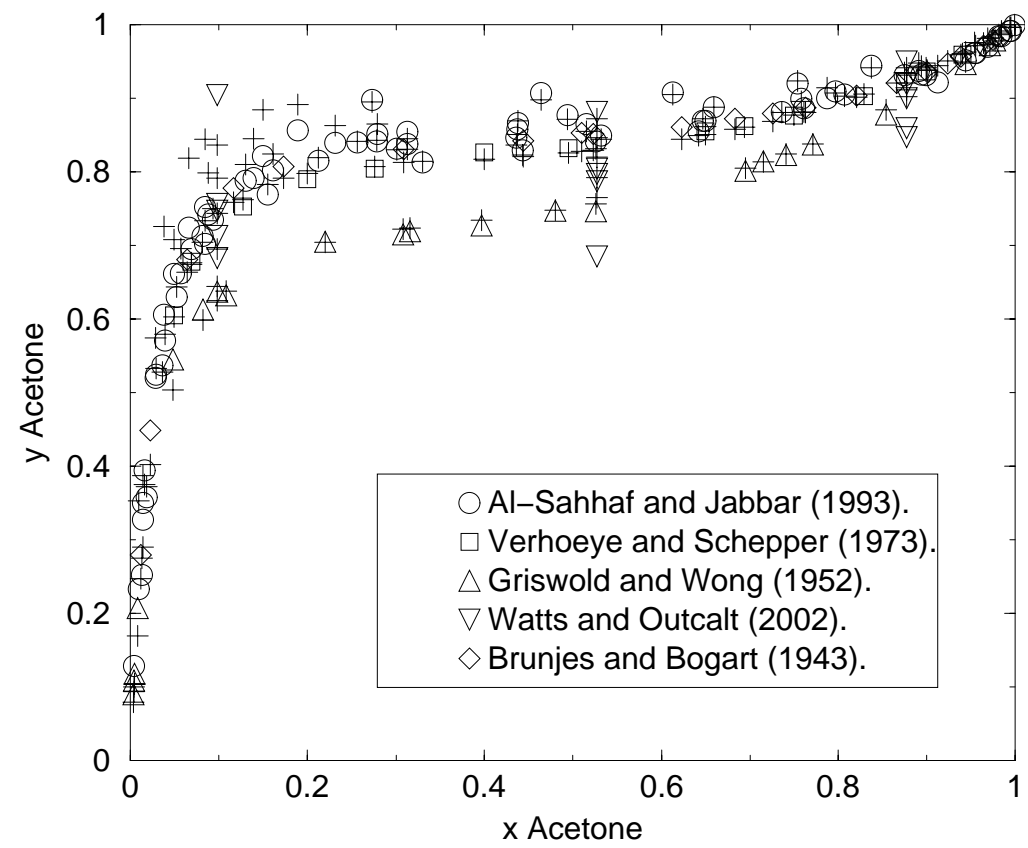

Figure 14. Measured (open symbols) and predicted (+) saturated vapor compositions of mixtures of water + acetone over a range of liquid composition and temperature. 


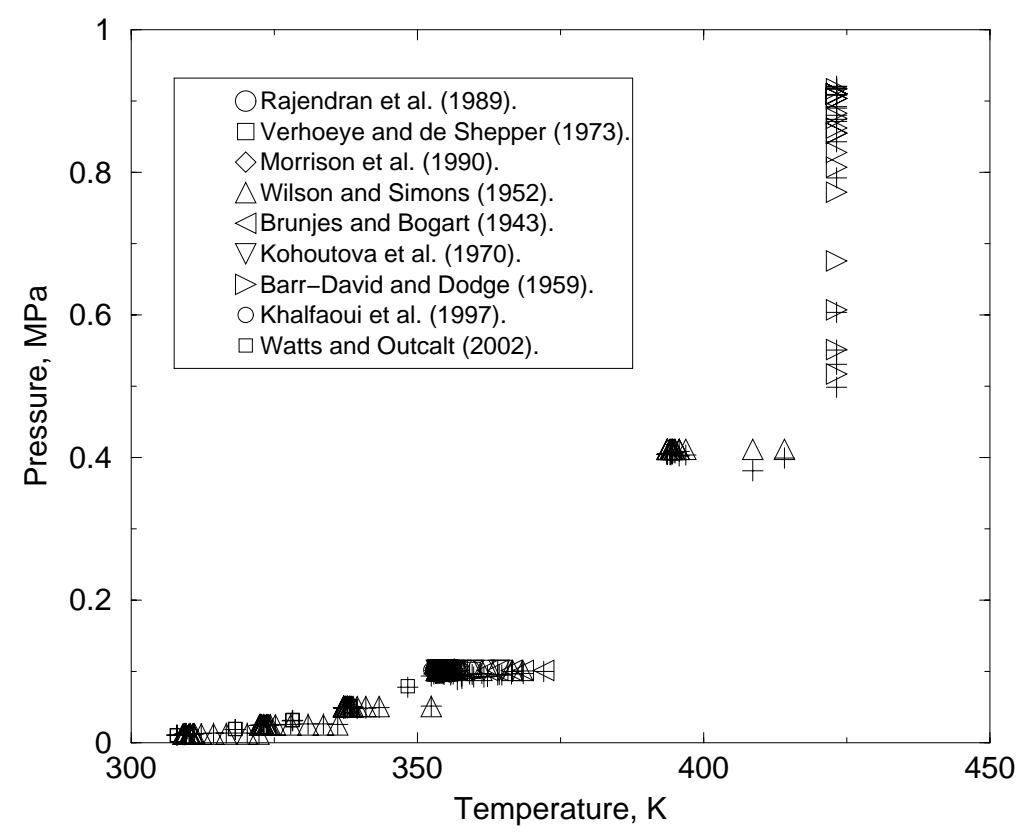

Figure 15. Measured (open symbols) and predicted (+) saturated vapor pressures for mixtures of water +2 -propanol over a range of composition and temperature.

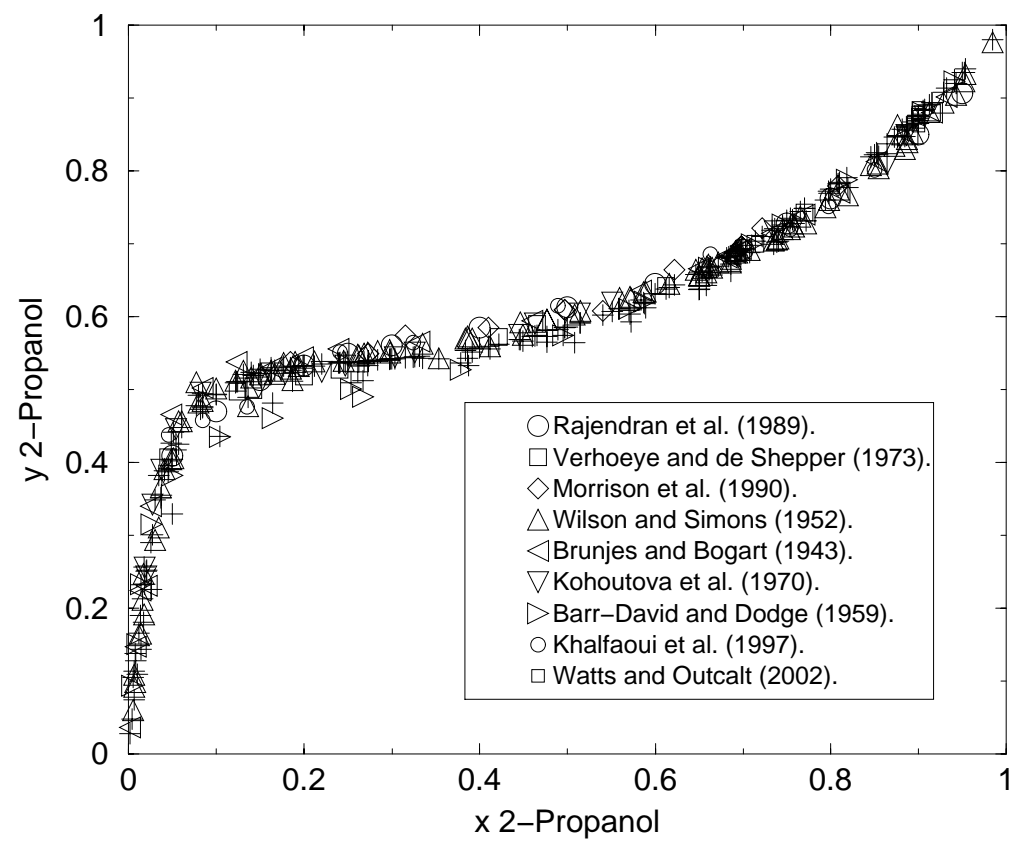

Figure 16. Measured (open symbols) and predicted (+) saturated vapor composition for mixtures of water +2 -propanol over a wide range of liquid composition and temperature. 


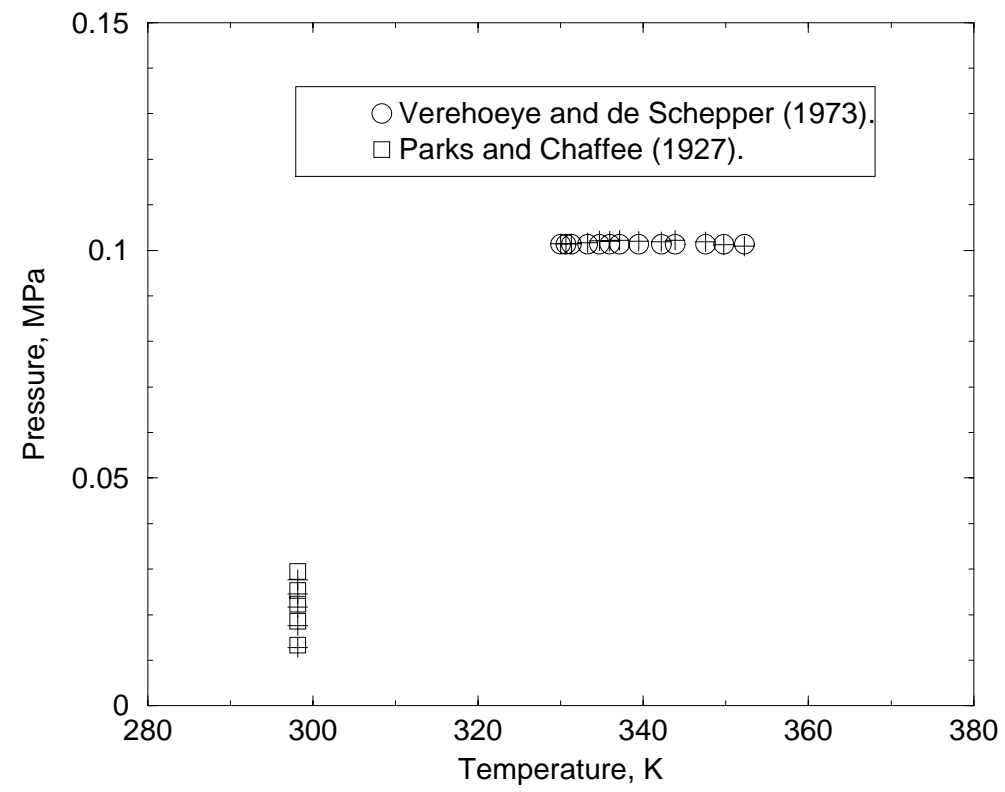

Figure 17. Measured (open symbols) and predicted $(+)$ saturated vapor pressure of acetone +2 propanol mixtures over an range of composition and temperature.

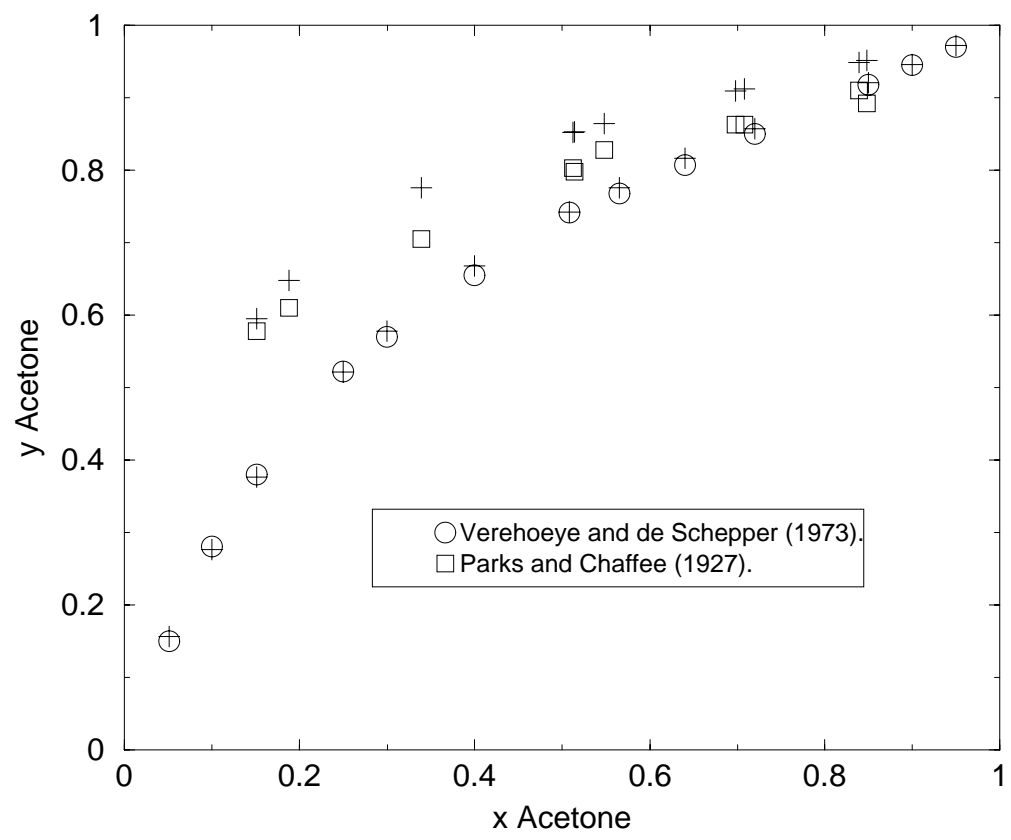

Figure 18. Measured (open symbols) and predicted (+) saturated vapor compositions of mixtures of acetone +2 -propanol over a range of composition and temperature. 


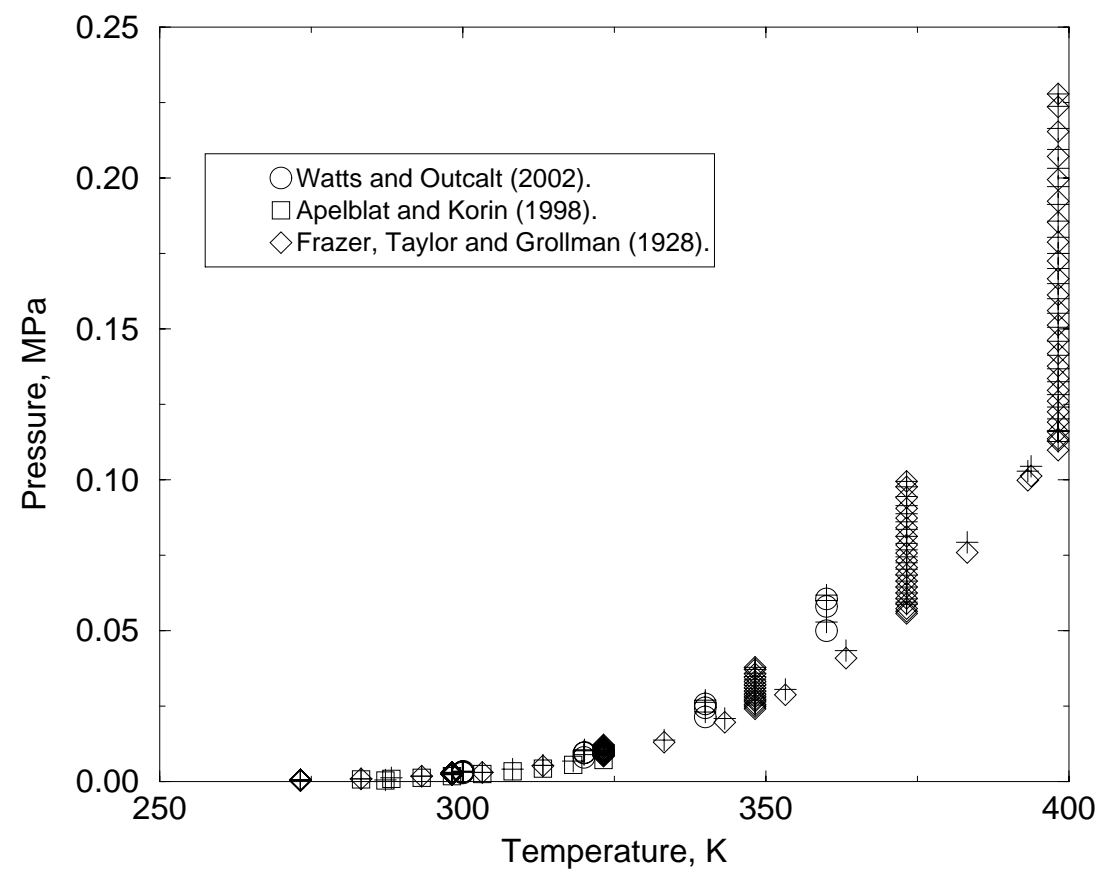

Figure 19. Measured (open symbols) and predicted (+) saturated vapor pressure for mixtures of water $+\mathrm{NaNO}_{3}$ to 27 molal in salt over a wide range of temperature.

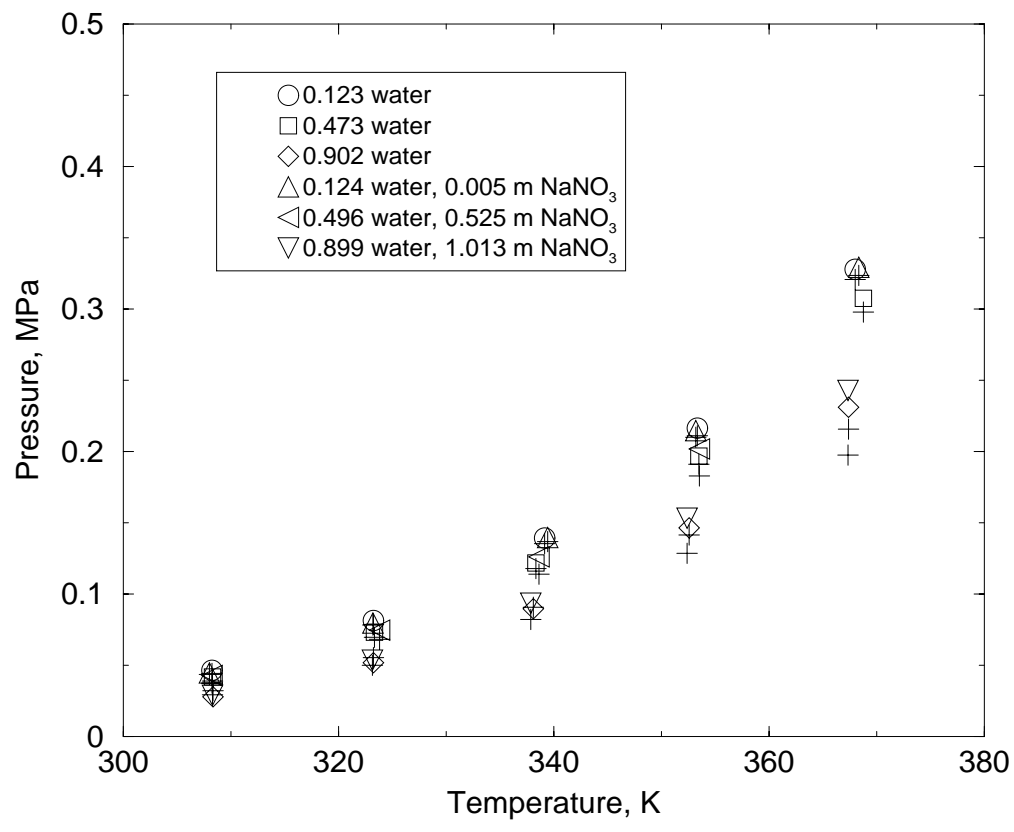

Figure 20. Measured (open symbols, Watts and Outcalt, 2002) and predicted (+) saturated vapor pressures for mixtures of water + acetone $+\mathrm{NaNO}_{3}$ over a range of composition and temperature. Water composition is in salt-free mole fraction. 


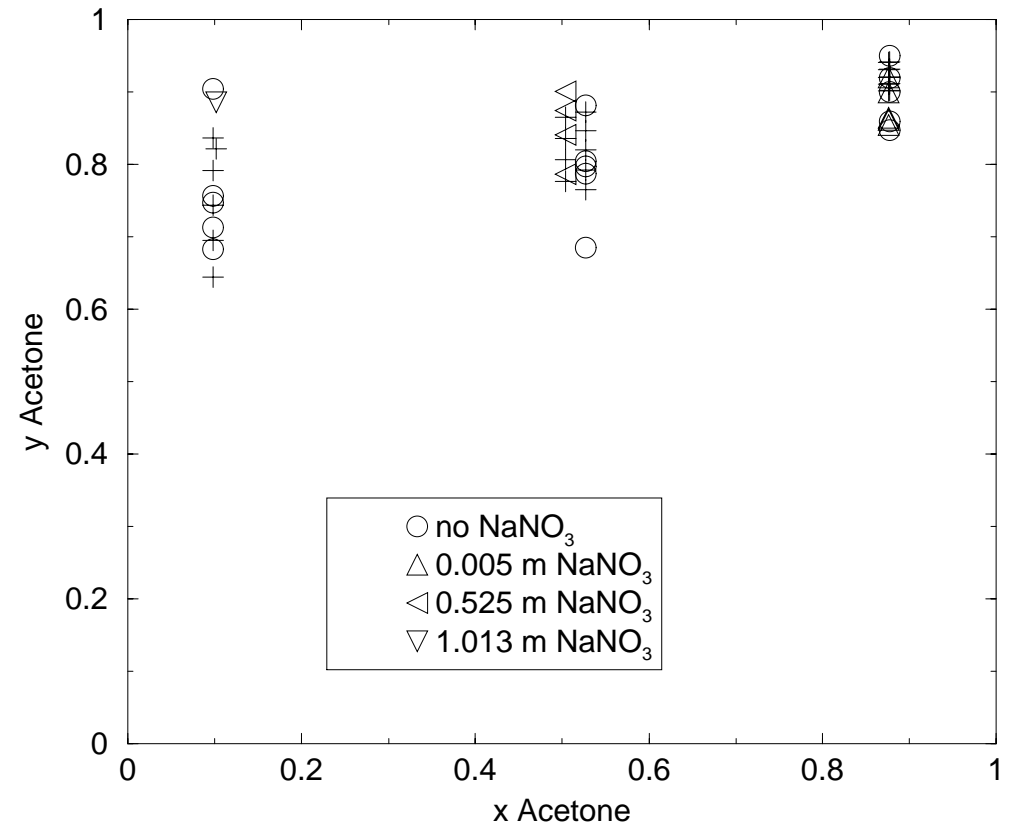

Figure 21. Measured (open symbols, Watts and Outcalt, 2002) and predicted (+) saturated vapor compositions for mixtures of water + acetone $+\mathrm{NaNO}_{3}$ over a range of composition and temperature. Salt-free mole fractions are used.

Figure 22. Measured (open symbols, Watts and Outcalt, 2002) and predicted (+) saturated vapor

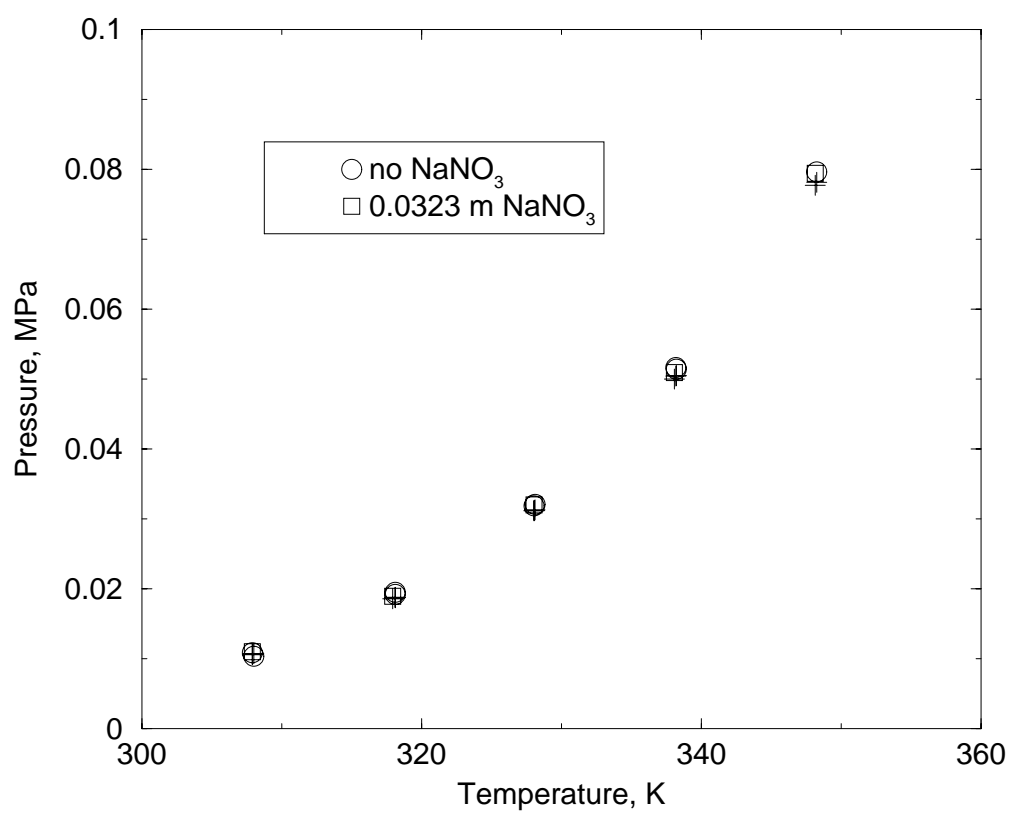

pressures for a mixture of water + 2-propanol with and without $\mathrm{NaNO}_{3}$ over a range of temperature. Salt-free mole fractions are used. 


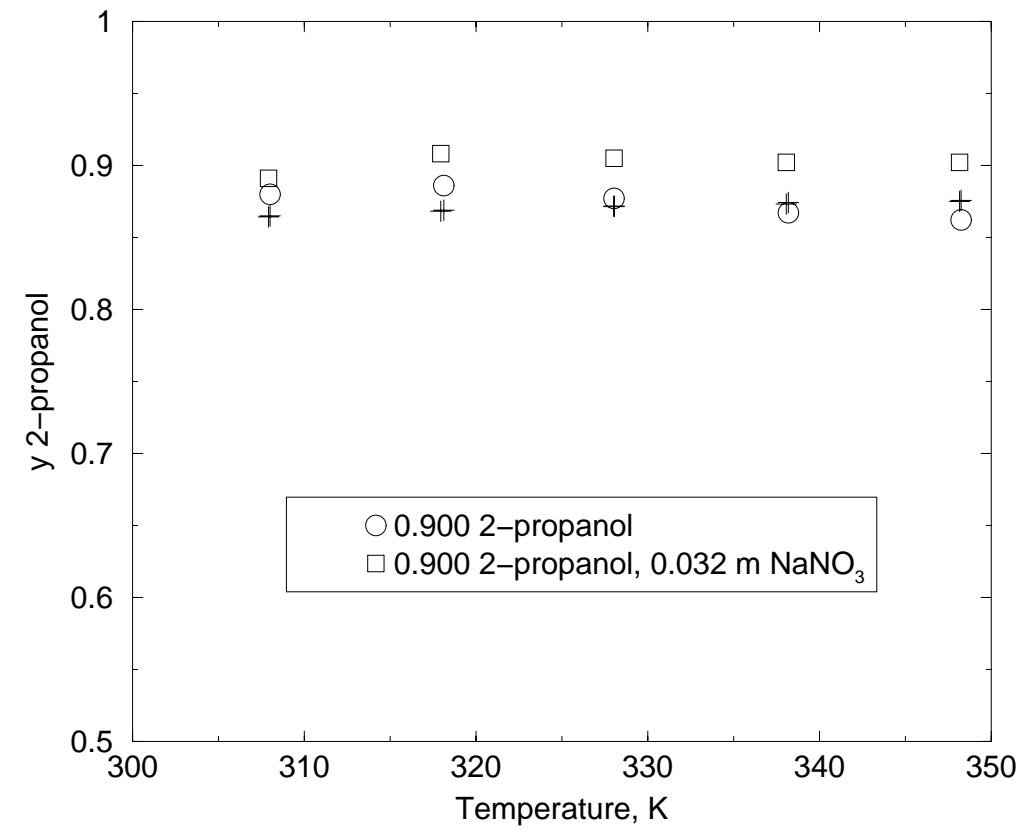

Figure 23. Measured (open symbols, Watts and Outcalt, 2002) and predicted (+) vapor compositions for mixtures of water +2 -propanol with and without $\mathrm{NaNO}_{3}$ added over a range of temperature.

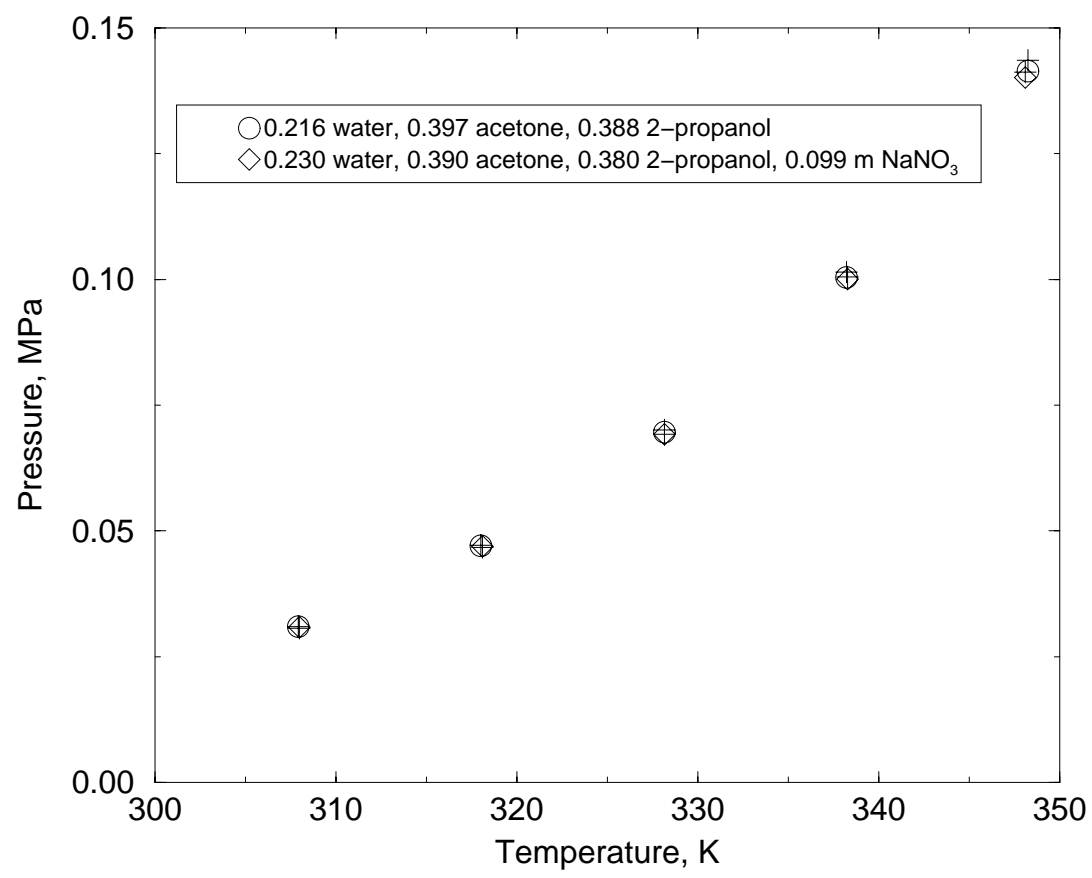

Figure 24. Measured (open symbols, Watts and Outcalt, 2002) and predicted (+) saturated vapor pressures for a mixture of water + acetone +2 -propanol with and without $\mathrm{NaNO}_{3}$ added over a range of temperature. Salt-free mole fractions are used. 


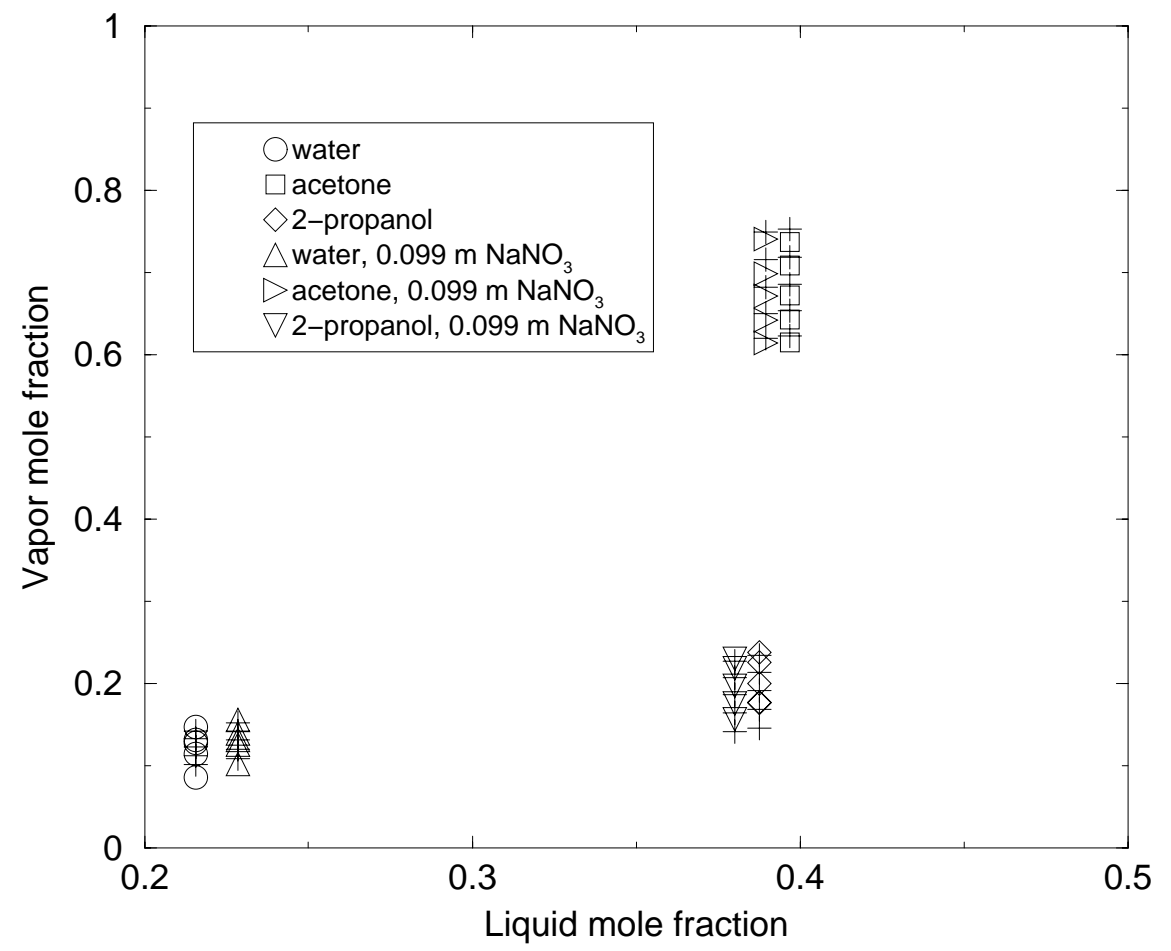

Figure 25. Measured (open symbols, Watts and Outcalt, 2002) and predicted (+) saturated vapor pressure of mixtures of water + acetone +2 -propanol with and without $\mathrm{NaNO}_{3}$ at five temperatures. Mole fractions are on a salt free basis. 


\section{Relevance, Impact, and Technology Transfer}

\section{Publications and Presentations}

L. A. Watts, Vapor-Liquid Equilibrium Prediction of Mixed Solvent Electrolyte Solutions with the Peng-Robinson-Stryjek-Vera Equation of State, in preparation.

L. A. Watts and S. Outcalt, VLE and Phase Density Measurements for the System Water + Acetone +2 -Propanol $+\mathrm{NaNO}_{3}$, in preparation .

L. A. Watts, Vapor-liquid Equilibrium of Mixed Solvent Electrolyte Solutions: Measurements and Models, $9^{\text {th }}$ Biennial International Spectrum Conference, American Nuclear Society, Reno, Nevada, Aug. 4-8, 2002.

C. D. Holcomb, L. A. Watts, S. L. Outcalt, B. Louie, M. E. Mullins, and T. N. Rogers, Measurements and Models for Hazardous Chemical and Mixed Wastes, EMSP National Workshop, Atlanta, Georgia, April 24-28, 2000.

Watts, L. A. and B. Louie, Apparatus for Measuring Vapor-Liquid Equilibria and Phase Densities of Complex Aqueous Solutions. Int. J. Thermophysics 21(5): 1139-1151, 2000.

L. A. Watts, C. D. Holcomb, S. L. Outcalt, and B. Louie, Measurements and Models for Hazardous Chemical and Mixed Wastes, Fourteenth Symposium on Thermophysical Properties, Boulder, Colorado, June 25-30, 2000.

C. D. Holcomb, L. A. Watts, S. L. Outcalt, B. Louie, M. E. Mullins, and T. N. Rogers, Measurements and Models for Hazardous Chemical and Mixed Wastes, EMSP Workshop, Chicago, Illinois, July 27-30, 1998.

L. A. Watts, Modeling Mixed Solvent Electrolyte Solutions using a Cubic Equation of State, Thirteenth Symposium on Thermophysical Properties, Boulder, Colorado, June 22-27, 1997.

L. A. Watts and B. Louie, A New Apparatus for Measuring VLE and Phase Density of AqueousOrganic-Salt Solutions, Thirteenth Symposium on Thermophysical Properties, Boulder, Colorado, June 22-27, 1997.

\section{Collaborations Information}

This project has been conducted in formal collaboration with Dr. Michael Mullins and Dr. Tony Rogers from Michigan Technological University (MTU). This arrangement was devised to obtain complementary measurements, with NIST performing VLE and density measurements, and 
MTU performing ebouliometric measurements to obtain infinite dilution activity coefficients. Pariyachat Chatkun Na Ayuttaya, a Ph.D. student from MTU, came to NIST in Boulder to make measurements on a small-volume VLE apparatus, and Dr. Watts from NIST visited MTU to consult on modeling progress and measurements. We also held informal meetings at scientific gatherings where we were in attendance.

The project has also been contacted by various DoE researchers with problems directly related to the work, and those of a similar nature concerning VLE and density measurements and prediction. Modeling mixed solvent electrolyte systems is an area of interest to many, and we have been contacted by such diverse groups as researchers in Azerbaijan designing heat pumps to energy producers trying to predict methane solubility in process streams containing salts and other dissolved solids. AIChE's Design Institute for Physical Properties (DIPPR) will assist in dissemination of this information through the 911 project at MTU.

\section{Personnel Supported:}

The NIST portion of the funding for this project supported the following personnel:

Dr. Laurel A. Watts, NIST

Dr. Cynthia D. Holcomb, NIST

Stephanie L. Outcalt, NIST

Dr. Beverly Louie, NIST

Pariyachat Chatkun Na Ayuttaya, a PhD graduate student from MTU performed experiments during her stay at NIST.

Brianna McFarlane, a BS student at Colorado School of Mines, Golden, CO.

\section{Future Work}

Future work for this research may include developing a better density correlation for the liquid phase, and investigating other local composition models for the Gibbs free energy calculation. Extension of the model to include salt solubility prediction and ionic speciation present in the liquid phase would also be possible. The model could be extended to other fluids and salts of interest. This would involve measuring the VLE and infinite dilution activity coefficient of additional water + organic solvent + salts over a wider range of salt composition.

\section{Literature Cited}


Al-Sahhaf, T. A. and N. J. Jabbar (1993). Vapor-liquid equilibrium of the acetone-water-salt system. J. Chem. Eng. Data 38: 522-526.

Ambrose, D., C. H. S. Sprake and R. Townsend (1975). Thermodynamic properties of organic oxygen compounds. XXXVII. Vapour pressures of methanol, ethanol, pentan-1-ol, and octan-1-ol from the normal boiling temperature to the critical temperature. J. Chem. Thermo. 7: 185-190.

Ambrose, D. and C. H. S. Sprake (1970). Thermodynamic properties of organic oxygen compounds. XXV. Vapour pressures and normal boiling temperatures of aliphatic alcohols. J. Chem. Thermo. 2: 631-645.

Apelblat, A. and E. Korin (1998). The vapor pressures of saturated aqueous solutions of sodium chloride, sodium bromide, sodium nitrate, sodium nitrite, potassium iodate, and rubidium chloride at temperatures from $227 \mathrm{~K}$ to $323 \mathrm{~K}$. J. Chem. Thermo. 30: 59-71.

Barr-David, F. and B. F. Dodge (1959). Vapor-liquid equilibrium at high pressures: the systems ethanol-water and 2-propanol-water. J. Chem. Eng. Data 4: 107-120.

Brunjes, A. S. and M. J. P. Bogart (1943). Vapor-liquid equilibria for commercially important systems of organic solvents. Ind. Eng. Chem. 35: 255-260.

Campbell, A. N. and R. M. Chatterjee (1968). Orthobaric data of certain pure liquids in the neighborhood of the critical point. Can. J. Chem. 46: 575-581.

Chen, C.-C. and L. B. Evans (1986). A local composition model for the excess Gibbs energy of aqueous electrolyte systems. AIChE J. 32: 444-454.

Chen, C.-C., H. I. Britt, J. F. Boston and L. B. Evans (1982). Local composition model for excess Gibbs energy of electrolyte systems. AIChE J. 28: 588-596.

Dannhauser, W. and L. W. Bahe (1964). Dielectric constant of hydrogen bonded liquids. III. Superheated alcohols. J. Chem. Phys. 40: 3058-3066.

Frazer, J. C., R. K. Tayler and A. Grollman (1928). Two-phase liquid-vapor isothermal systems, vapor pressure lowering. International Critical Tables, Vol. III. National Research Council, New York: McGraw-Hill.

French, H. T. (1989). Excess enthalpies of (acetone + water) at 278.15, 288.15, 298.15, 308.15, 318.15, and 323.15 K. J. Chem.Thermo. 21: 801-809.

Griswold, J. and S. Y. Wong (1952). Phase-equilibria of the acetone-methanol-water system 
from $100^{\circ} \mathrm{C}$ into the critical region. Chem. Eng. Progress Symp. Ser. 3, 48 : 18-34.

Hales, J. L. and J. H. Ellender (1976). Liquid densities from 293 to $490 \mathrm{~K}$ of nine aliphatic alcohols. J. Chem. Thermo. 8: 1177-1184.

Harvey, A. H. and J. M. Prausnitz (1989). Thermodynamics of high-pressure aqueous systems containing gases and salts. AIChE J. 35: 635-644.

Harvey, A. H. and J. M. Prausnitz (1987). Dielectric constants of fluid mixtures over a wide range of temperature and density. J. Sol. Chem. 16: 857-869.

Khalfaoui, B., A. H. Meniai and R. Borja (1997). Thermodynamic properties of water + normal alcohols and vapor-liquid equilibria for binary systems of methanol or 2-propanol with water. Fluid Phase Eq. 127: 181-190.

Kohoutova, J., J. Suska, J. P. Novak and J. Pick (1970). Liquid-vapor equilibrium. XLV. System methanol-2-propanol-water. Coll. Czech. Chem. Comm. 35: 3210-3222.

Kubota, H., Y. Tanaka and T. Makita (1987). Volumetric behavior of pure alcohols and their water mixtures under high pressures. Int. J. Thermophysics 8: 47-70.

Mathias, P. M., T. Naheiri and E. M. Oh (1989). A density correction for the Peng-Robinson equation of state. Fluid Phase Eq. 47: 77-87.

Mock, B., L. B. Evans and C.-C. Chen (1986). Thermodynamic representation of phase equilibria of mixed-solvent electrolyte systems. AIChE J. 32: 1655-1664.

Morrison, J. F., J. C. Baker, H. C. M. III, K. E. Newman, T. D. Walter, J. D. Massie, R. L. Perry and P. T. Cummings (1990). Experimental measurement of vapor-liquid equilibrium in alcohol/water/salt systems. J. Chem. Eng. Data 35: 395-404.

Parks, G. S. and C. S. Chafee (1927). Some physical-chemical properties of mixtures of acetone and iso-propyl alcohol. J. Phys. Chem. 31: 439-447.

Peng, D.-Y. and D. B. Robinson (1976). A new two-constant equation of state. Ind. Eng. Chem. Fund. 15: 59-64.

Pitzer, K. S. and J. M. Simonson (1986). Thermodynamics of multicomponent, miscible, ionic systems: Theory and equations. J. Phys. Chem. 90: 3005-3009.

Rajendran, M., S. Renganarayanan and D. Srinivasan (1989). Salt effect in phase equilibria: Effect of dissolved inorganic salts on the liquid-liquid equilibria of benzene-2-propanolwater system and the vapor-liquid equilibria of its constituent binaries. Fluid Phase Eq. 
50: $133-164$.

Renon, H. and J. M. Prausnitz (1969). Derivation of the three-parameter Wilson equation for the excess Gibbs energy of liquid mixtures. AIChE J. 15: 785.

Saleh, M. A., D. Biswas, O. Ahmed, S. Akhtar and M. Habibullah (1993). Volumetric and viscometric properties of water-acetone system. Chittagong Univ. Stud. Part II:Sci. 17: $127-136$.

Saul, A. and W. Wagner (1989). A fundamental equation of state fpr water covering the range from the melting line to $1273 \mathrm{~K}$ at pressures up to $25,000 \mathrm{MPa}$. J. Phys. Chem. Ref. Data 18: $1537-1564$.

Stryjek, R. and J. H. Vera (1986a). An improved Peng-Robinson equation of state for pure compounds and mixtures. Can. J. Chem. Eng. 64: 323-333.

Stryjek, R. and J. H. Vera (1986b). PRSV--An improved Peng-Robinson equation of state with new mixing rules for strongly nonideal mixtures. Can. J. Chem. Eng. 64: 334-340.

Takiguchi, Y. and M. Uematsu (1996). Densities for liquid ethanol in the temperature range from $310 \mathrm{~K}$ to $480 \mathrm{~K}$ at pressures up to $200 \mathrm{MPa}$. J. Chem. Thermo. 28: 7-16.

Verhoeye, L. and H. de Schepper (1973). The vapour-liquid equilibria of the binary, ternary and quanternary systems formed by acetone, methanol, propan-2-ol, and water. J. Appl. Chem. Biotechnol. 23: 607-619.

Watts, L. A. and B. Louie (2000). Apparatus for measuring vapor-liquid equilibria and phase densities of complex aqueous solutions. Int. J. Thermophysics 21: 1139-1151.

Watts, L. A., Vapor-Liquid Equilibrium Prediction of Mixed Solvent Electrolyte Solutions With the Peng-Robinson-Stryjek-Vera Equation of State, in preparation.

Watts, L. A. and S. Outcalt, VLE and Phase Density Measurements for the System Water + Acetone +2 -Propanol $+\mathrm{NaNO}_{3}$, in preparation .

Wilhoit, R. C. and B. J. Zwolinski (1973). Supplement no.1 (2-propanol). J. Phys. Chem. Ref. Data 2.

Wilson, A. and E. L. Simons (1952). Vapor-liquid equilibrium: 2-propanol-water system. Ind. Eng. Chem. 44: 2214-2219.

Wong, D. S. H. and S. I. Sandler (1992). A theoretically correct mixing rule for cubic equations of state. AIChE J. 38: 671-680. 
Wong, D. S. H., H. Orbey and S. I. Sandler (1992). Equation of mixing rule for nonideal mixtures using available activity coefficient model parameters and that allows extrapolation over large ranges of temperature and pressure. Ind. Eng. Chem. Res. 31: 2033-2039.

Zhao, E. and B. C.-Y. Lu (1998). Representation of electrolyte solution properties by means of the Peng-Robinson-Stryjek-Vera Equation of State. Ind. Eng. Chem. Res. 37: 1619-1624.

Zuo, Y.-X. and T.-M. Guo (1991). Extension of the Patel-Teja equation of state to the prediction of the solubility of natural gas in formation water. Chem. Eng. Sci. 46: 3251-3258. 